Check for updates

Cite this: RSC Adv., 2017, 7, 26608

Received 14th March 2017

Accepted 1st May 2017

DOI: $10.1039 / \mathrm{c} 7 \mathrm{ra02746j}$

rsc.li/rsc-advances

\section{Vesicles: self-assembly beyond biological lipids}

\author{
Appa Rao Sapala, Sameer Dhawan and V. Haridas (D)*
}

Self-assembly is a powerful strategy for the development of various intricate supramolecular architectures through non-covalent interactions. Non-covalent interactions can be utilized to produce tubular, vesicular, spherical, fibril, toroidal and helical morphologies. Amongst different types of morphologies, vesicles are of great interest due to their potential use in the drug encapsulation, drug delivery, and as nanoscale reaction vessels. These applications inspired chemists to develop various synthetic molecules that display vesicular self-assembly. This review presents recent examples of synthetic systems that show vesicular self-assembly.

\section{Introduction}

Supramolecular chemistry is the chemistry of non-covalent interactions that mostly deals with molecular self-assembly ${ }^{1}$ and molecular recognition between host and guest. ${ }^{2-4}$ The major intermolecular interactions responsible for the assembly are hydrogen bonds, metal coordination, hydrophobic, van der Waals, $\pi-\pi$ and electrostatic. ${ }^{5}$ Many vital biological processes are controlled by these intermolecular interactions, hence they are intensely investigated.

Design of molecules that can produce predictable supramolecular architecture is a challenge for a chemist. ${ }^{6}$ The difficulty in predicting supramolecular assembly is due to the probability of a large number of possible non-covalent

Department of Chemistry, Indian Institute of Technology Delhi (IITD), Hauz Khas, New Delhi-110016, India. E-mail: haridasv@iitd.ac.in; Tel: +91 1126591380 interactions. Therefore, scientists synthesize molecules and analyse their organization, in order to understand the logic of molecular assembly. Despite a broad range of molecular structures available, it still remains a formidable challenge to address the relationship between chemical structure and supramolecular assembly. In this context, self-assembly is a powerful strategy for the synthesis of nanomaterials of precise dimensions. ${ }^{7}$

The key aim of scientists working in the area of self-assembly is to build novel molecules that can undergo spontaneous and predictable assembly through non-covalent interactions. Although the interactions are rather weak, the collective outputs are very robust resulting in stable functional materials. The key principles in molecular self-assembly are structural complementarity and molecular recognition.

Among various supramolecular structures, vesicles are of great interest due to their importance as drug delivery vehicles

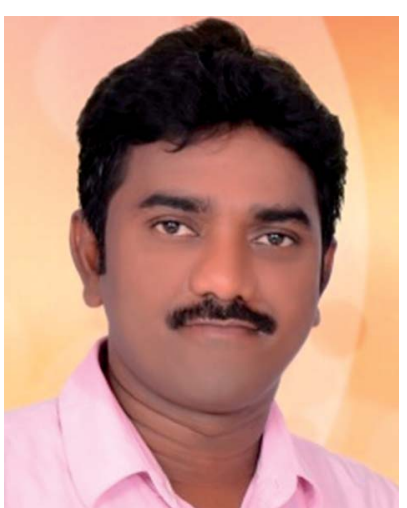

Appa Rao Sapala was born in Rajahmundry (1984), Andhra Pradesh, India. He received his bachelor's degree (2005) from the same place and MSc degree (2007) in Chemistry from Gitam College, Andhra University, Visakhapatnam. He had 3 years experience in G. V. K Bio Pvt. Ltd, Hyderabad. He qualified CSIR-JRF and has submitted his Ph.D. thesis entitled "Design, synthesis and vesicular selfassembly of acyclic, cyclic and lipid based molecules" at IIT Delhi under the guidance of Dr V. Haridas. He is currently working as senior research associate (SRA) in Albany Molecular Research In. Pvt. Ltd, Hyderabad.

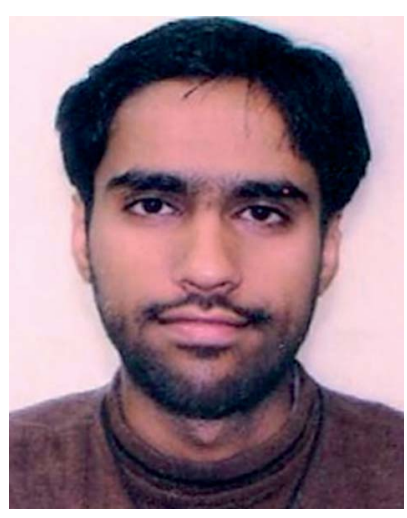

Sameer Dhawan was born in Punjab, India. He received his Masters in Chemistry in 2014 from Punjabi University, Patiala and Bachelor's from Guru Nanak Dev University, Amritsar in 2012. He was awarded with "Chancellor's Medal of excellence" by Hon'ble Governor of State in 2015 for his academic achievements. He had been selected for the INSPIRE fellowship in 2015 under SHE program of Department of Science \& Technology (DST), Govt. of India. Presently, he is working as a Ph.D. student at IIT Delhi under the supervision of $\mathrm{Dr} V$. Haridas. His research interests include the design and synthesis of stimuli-responsive self-assembling peptidomimetics. 
(a)

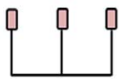

(d)

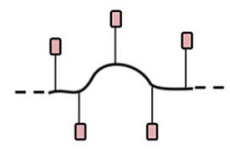

(b)
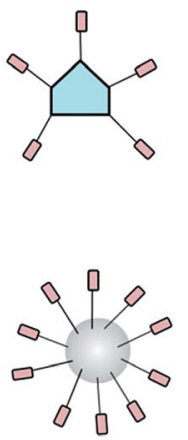

(c)

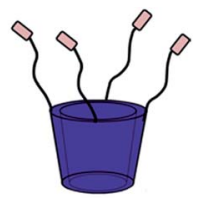

Fig. 1 Different topologies of scaffolds with functional groups: (a) 1-D linear arrangement (b) 2-D cyclic/macrocyclic (c) 3-D cavity containing scaffolds (cyclodextrin/calixarenes) (d) polymers/peptides (e) dendrimers/liposomes.

and stimuli responsive materials. ${ }^{89}$ This review presents recent advancements in supramolecular chemistry that deals with vesicles. Biological vesicles are majorly formed from the assembly of simple amphiphiles in water. ${ }^{10}$ Therefore, investigation of properties of vesicular structures remained the main concern for the scientists of various disciplines due to its immediate resemblance to natural lipid membranes. ${ }^{11}$ Amphiphiles, ${ }^{12}$ polymers ${ }^{13}$ peptides ${ }^{14}$ calixarene, ${ }^{15}$ cyclodextrin, ${ }^{16}$ curcubiturils, ${ }^{17}$ fullerenes ${ }^{18}$ and dendrimers ${ }^{19}$ are extensively used scaffolds for tailoring and controlling the molecular organization (Fig. 1).

Vesicles, in general, can be mono-lamellar, bi-lamellar or multi-lamellar; depending upon the number of layers they constitute. In the natural vesicles, amphiphilic building blocks form a bilayer arrangement in three dimensions. In polar solvents, the polar groups project outwards and expose to solvent due to solvophilic interactions. At the same time, the non-polar groups cluster together to form a bilayer. Phospholipids generally give rise to small uni-lamellar vesicles (SUV's) and giant uni-lamellar vesicles (GUV's) depending upon the size and 3D orientation of the molecular building blocks (Fig. 2).

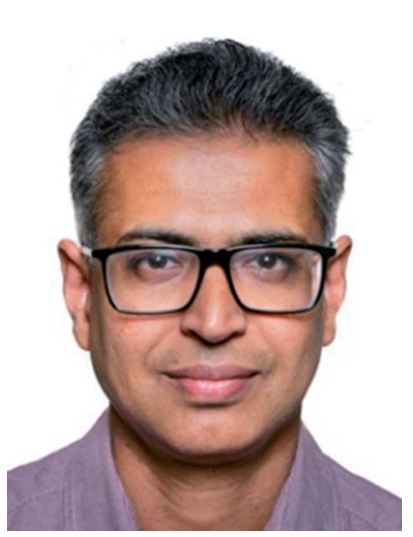

Dr V. Haridas is an Associate Professor in the Department of Chemistry at the Indian Institute of Technology Delhi (IITD), India. He finished his PhD under the guidance of Prof. D. Ranganathan (National Institute for Interdisciplinary Science and Technology, India). He did his post-doctoral studies with Prof. R. M. Ghadiri (The Scripps Research Institute, USA) and with Prof. Herbert Waldmann (Max Planck Institute, Germany). His research group at IIT Delhi is involved in the design and synthesis of dendrimers, and secondary structure mimetics. In addition to that the group is also working on various aspects of synthetic and bioorganic chemistry.

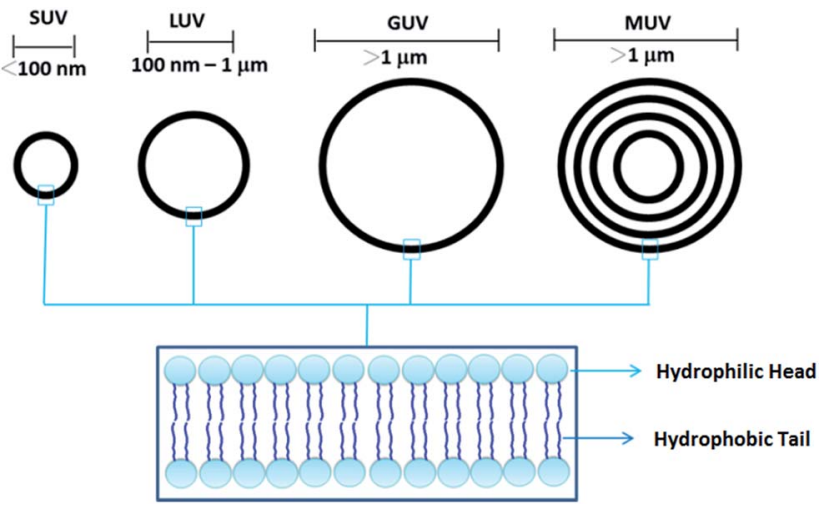

Fig. 2 Small unilamellar vesicles (SUVs), large unilamellar vesicles (LUVs), giant unilamellar vesicles (GUVs) and multiunilamellar vesicles (MUVs).

Giant vesicles are of micrometer dimensions and possess the attributes of biological membranes, hence it has been of intense interest in biological research. ${ }^{20}$

Preparation of vesicles is inspired by the synthetic procedures of liposomal preparation. As vesicles are metastable in solution, energy has to be infused into the bulk system to facilitate the self-assembly in solution. This energy is crucial for counteracting the unfavorable entropic factors associated with the self-assembling process. The energy required to obtain vesicles is usually provided by heat, stirring, ultrasonication, extrusion, freezing, drying or combinations of these. There are several unknown factors concerning the organization of molecules in the vesicular structure. Therefore, the prediction of the vesiculation process from novel molecules is a challenging endeavour for a chemist.

A remarkable development in the laboratory preparation of liposomes was outlined by Bangham and co-workers. ${ }^{21}$ The authors reported the synthesis of multilamellar vesicles from lecithin. The vesicles were of the order of $440 \mathrm{~nm}$. Though liposomes exemplify simplest vesicles, their applications are rather restricted due to the poor stability. ${ }^{22}$ Therefore, the research directed to the design and syntheses of molecules that assemble to form vesicles is a challenging endeavour.

In this review, we discuss various examples of vesicle forming molecules.

\subsection{Amphiphilic molecules}

Non-covalent interactions between molecules are central to biological systems. Amphiphiles are major class of molecules that form vesicular assembly. ${ }^{23}$ Amphiphiles orient themselves according to the nature of the solvent. The interactions between the amphiphiles minimize the surface energy and stabilization comes from solvophilic/solvophobic interactions. Amphiphilic molecules have an innate tendency to re-orient themselves to form a "head out" type arrangement in polar solvents, while maintaining a "tail-out" arrangement in non-polar solvents. Hence, the molecules arrange in a bilayer with cylindrical shape. Kunitake and co-workers, ${ }^{10}$ Ringsdorf and co-workers, ${ }^{12 a}$ 

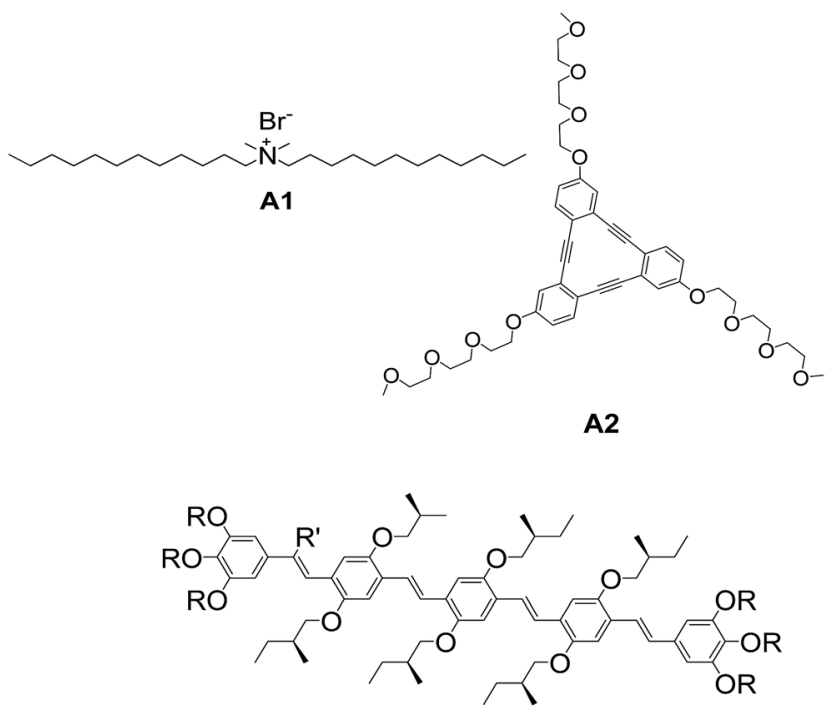

A3: $\mathrm{R}=\overparen{\mathrm{O}} \mathrm{O}$ O $\mathrm{O}-\mathrm{R}^{\prime}=\mathrm{H}$

A4: $\mathrm{R}=\longdiv { \mathrm { O } } \mathrm { O }$ O $\mathrm{O}^{-} \mathrm{R}^{\prime}=\mathrm{CN}$

Fig. 3 Chemical structure of didodecyldimethylammonium bromide A1. Chemical structures of discotic ortho-phenylene ethynylene macrocycle A2 and oligomers A3-A4.

and Engberts and co-workers ${ }^{24}$ have done pioneering work on vesicles from amphiphiles.

For the first time, in 1977, Kunitake and co-workers reported a synthetic amphiphile A1 (Fig. 3) which formed bilayer vesicles. $^{25}$ They demonstrated the vesicle formation from aqueous solution of didodecyldimethylammonium bromide.

Tew and co-workers reported a novel class of amphiphilic triangular macrocycle A2 (Fig. 3) and their spontaneous assembly into vesicular structures. ${ }^{26}$ The triangular molecule $\mathbf{A 2}$ self-assembled to spherical vesicles in water. The hollow interior was evident from atomic force microscopy (AFM) height images. Staining technique was also used for confirming the hollow interior. This is the first example of a discotic liquid

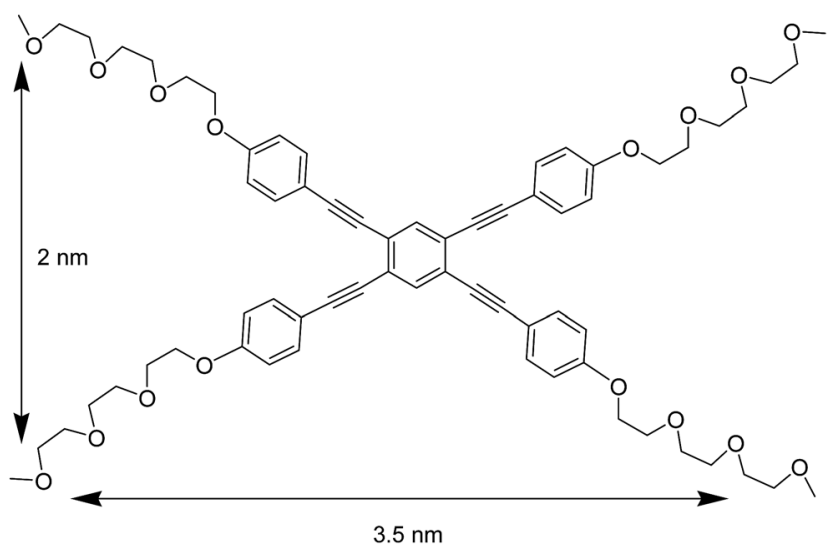

A5 crystalline molecule forming vesicular assembly. Vesicles were also reported from linear oligo(phenylene vinylene) amphiphiles A3-A4 by Meijer and co-workers (Fig. 3). ${ }^{27}$

Sánchez and co-workers synthesized rectangular amphiphile A5 (Fig. 4) and studied their self-assembling features. ${ }^{28}$ The vesicular assembly of rectangular oligo(phenylene ethylene) amphiphile in a mixture of acetonitrile : water was demonstrated by transmission electron microscopy (TEM) and AFM. The authors observed the concentration dependent selfassembly of A5 into toroids and vesicles. The concentration dependent NMR and UV-Vis experiments demonstrated the involvement of non-covalent interactions in the association of amphiphiles.

Raghavan and co-workers reported a novel method for the synthesis of reverse vesicles in non-polar organic solvents such as cyclohexane and $n$-hexane. Vesicles were formed by the assembly of lecithin A6 and C4-lecithin A7 (Fig. 5) in oil and were of $60-250 \mathrm{~nm}$ in diameter. ${ }^{29}$ The vesicles were characterized by ultramicroscopy and small-angle neutron scattering (SANS) studies. The morphological transformation of the reverse vesicles to cylinder was induced by the addition of sodium chloride. Authors reported that sodium chloride facilitated the weak interactions between the two lipids, which is attributed to the electrostatic interactions between $\mathrm{Na}^{+} / \mathrm{Cl}^{-}$ions and positive/negative charges on the lipid head groups. They also demonstrated that the curvature can be induced by the coassembly of a set of lecithins of unequal chain length which causes the morphological transformation in the presence of inorganic salts.

Sánchez and co-workers reported the vesicular self-assembly from aryl triazole amphiphile $\mathbf{A 8}$ (Fig. 6) in acetonitrile. ${ }^{30}$ The authors postulated that the formation of vesicular assembly by A8 might be due to the dimers formed by $\mathrm{CH}-\pi \mathrm{H}$-bonds involving the lateral naphthalene units. The dimers further assembled to produce the vesicular structures. Authors have also studied the disruption of morphology upon the binding of bromide anions.

Saha and co-workers synthesized and studied the selfassembly of amphiphilic hexaamide macrocycles A9 and A10 (Fig. 7). ${ }^{31}$ Interestingly, the authors observed open-shell and closed-shell assemblies depending upon the side groups. A9 formed closed-shell vesicles in THF, while $\mathbf{A 1 0}$ revealed the open-shell assembly. The difference in the self-assembly of $\mathbf{A 9}$ and $\mathbf{A 1 0}$ is attributed to the difference in their stacking patterns.

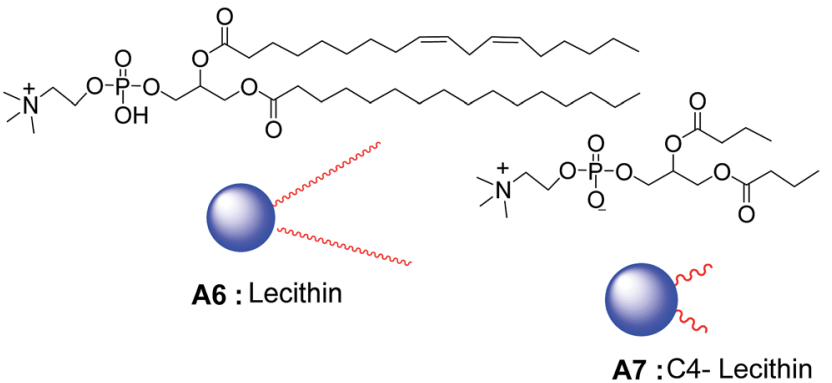

Fig. 5 Chemical structures of lecithin A6 and C4-lecithin A7. 


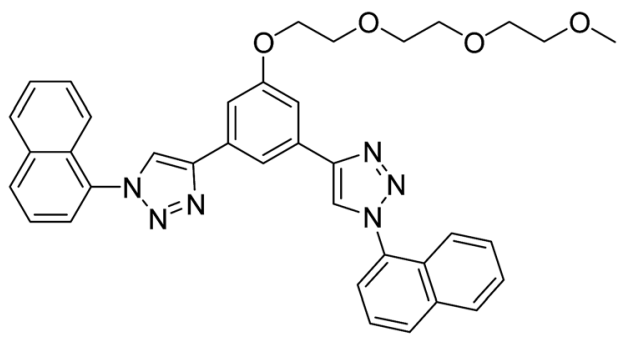

A8

Fig. 6 Chemical structure of aryl triazole amphiphile A8.

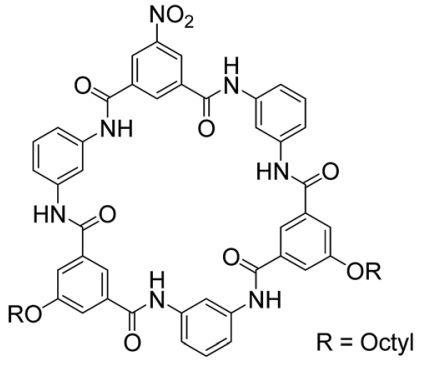

A9

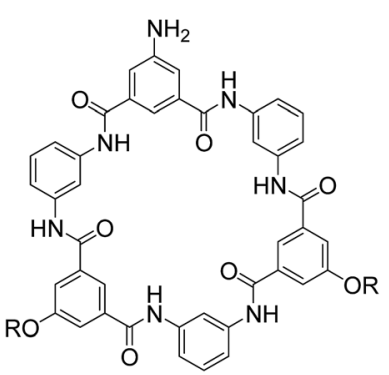

A10
Fig. 7 Chemical structures of oligomers A9-A10.

A10 stacks differently from $\mathbf{A 9}$ in bilayer membranes to avoid the electrostatic repulsions between $\mathrm{N}$-lone pair electrons of $-\mathrm{NH}_{2}$ group leading to the formation of open-shell vesicles. The authors also demonstrated the transformation of open-shell vesicles of A10 to closed shell vesicles by adding water into it and open/closed-shell vesicles of A9-A10 to nanotubes upon addition of acetic acid. These self-assembled structures were characterized by dynamic light scattering (DLS), scanning electron microscopy (SEM), TEM and AFM.

\subsection{Calixarene-based molecules}

Regen and co-workers reported vesicular assembly from calix[6] arene $\mathbf{A 1 1}$ (Fig. 8). ${ }^{32}$ Vesicle dispersion was observed by injecting a THF solution of $\mathbf{A 1 1}$ into water. Interestingly, vesicles were not observed when A12 was injected in the same way. The failure of vesicle formation from A12 might be due to the presence of $t$ butyl groups which prevented the formation of lamellar phase.

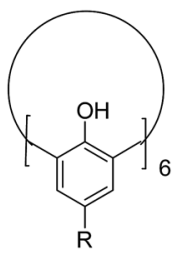

A11: $\mathrm{R}=\mathrm{H}$

A12: $\mathrm{R}=\mathrm{C}\left(\mathrm{CH}_{3}\right)_{3}$
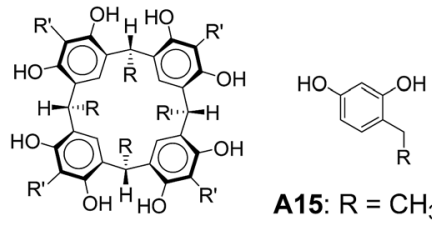

A15: $\mathrm{R}=\mathrm{CH}_{3}\left(\mathrm{CH}_{2}\right)_{16}$
Fig. 8 Chemical structures of calixarene based molecules A11-A15
A13: $\mathrm{R}=\mathrm{CH}_{3}\left(\mathrm{CH}_{2}\right)_{16}, \mathrm{R}^{\prime}=\mathrm{H}$

A14: $\mathrm{R}=\mathrm{CH}_{3}\left(\mathrm{CH}_{2}\right)_{16}, \mathrm{R}^{\prime}=\mathrm{OH}$

These results highlight the key role of geometry and molecular structure in defining the morphology of aggregates.

Tanaka and co-workers reported the vesicular assembly from calixarene derivatives A13 and A14 (Fig. 8). ${ }^{33}$ They demonstrated that the amphiphilic polyhydroxy macrocycles A13 and A14 formed vesicles in comparison to mono-alkyl phenol derivative A15.

The vesicles were prepared by injecting the solution of $\mathbf{A 1 3}$ or A14 in THF into a HEPES-Tris buffer solution (HEPES $=2$-[4(hydroxyethyl)piperazine-1-yl]ethanesulfonic acid, Tris = tris(hydroxymethyl)aminomethane) at $60{ }^{\circ} \mathrm{C}$. The stability of vesicles in water was checked after two weeks by TEM and AFM. The authors confirmed the bilayer structures of A13 using differential scanning calorimetry (DSC) measurements and suggested that the vesicles were composed of unilamellar membranes. A15 formed micelle-like aggregates under the same condition. The failure of $\mathbf{A 1 5}$ to form vesicles revealed the importance of the cyclic structure in the formation of vesicles.

Lee and co-workers reported the stimuli responsive nanocapsules from amphiphilic calixarenes A16-A17 (Fig. 9) in aqueous solution by varying $\mathrm{pH}$ or hydrophilic chain length of the molecules. ${ }^{34}$ TEM images and DLS data of A16 and A17 revealed the sizes of vesicles as $200 \mathrm{~nm}$ and $35 \mathrm{~nm}$ respectively, which clearly indicated the effect of longer hydrophilic chains on self-assembly. TEM images showed a contrast between the periphery and the centre of the sphere supporting the hollow nature of vesicles. Interestingly, the transformation of vesicular

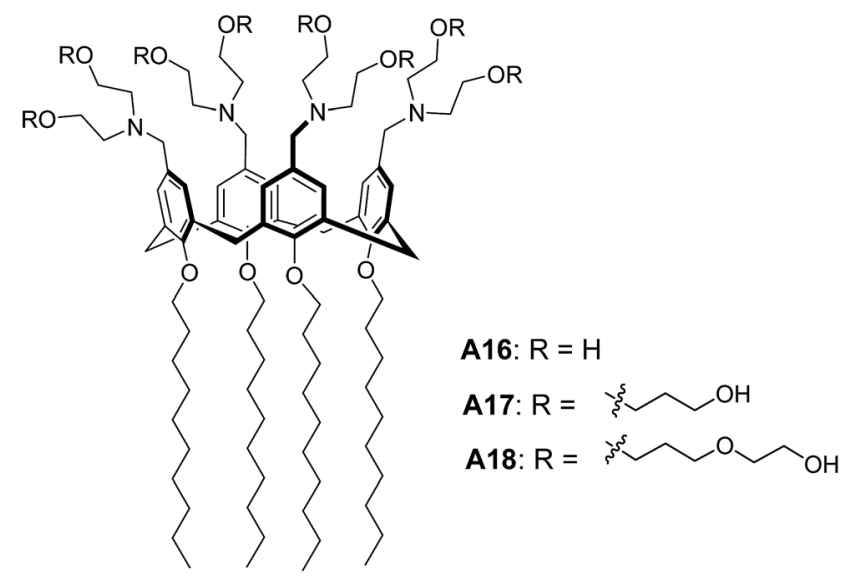

Fig. 9 Chemical structures of calixarene derivatives A16-A18.<smiles>CCCCCCCc1cc(CC)cc(C(=O)O)c1O</smiles>

A19<smiles></smiles>

A19 $\Rightarrow$ Vesicles

A20 A21 $\Rightarrow$ No Vesicles 
structures of A16 to micellar structures was observed with the decrease in $\mathrm{pH}$. They also reported that amphiphilic calixarene A18 (Fig. 9) based on oligo(ethylene oxide) chains selfassembled to form spherical micelles.

Meier and co-workers have synthesized calix[4]arene A19 (Fig. 10) bearing dodecyl chains at the small $\operatorname{rim}\left(\mathrm{R}=n \mathrm{C}_{12} \mathrm{H}_{25}\right)$ and carboxylic groups $[\mathrm{R}=\mathrm{COOH}]$ at the large rim. ${ }^{35}$ These compounds formed vesicles of various sizes with a bilayered membrane in basic medium ( $0.1 \mathrm{~N}$ aq. ammonia). The authors also investigated the self-assembly of amphiphilic calix[4]arenes by varying the head group to trimethyl ammonium A20-A21 (Fig. 10), which provided high water solubility with no aggregation. The formation of vesicles in $\mathbf{A 1 9}$ is attributed to the hydrogen bonding and absence of aggregation in A20-A21 is due to the ionic repulsion between the quaternary head groups.

Rémita and co-workers synthesized and studied the selfassembly of calix[6] arene $\mathbf{A 2 2}$ (Fig. 11) in water. ${ }^{36}$ The calixarene was functionalized at the small rim by three imidazolyl arms and at the large rim by three hydrophilic sulfonate groups. They reported the stimuli responsive aggregation by introducing the imidazole group in the amphiphilic calix[6] arene A22. Formation of multi-lamellar vesicles of sizes about 50$250 \mathrm{~nm}$ at $\mathrm{pH} 7.8$ was confirmed by using TEM, AFM and DLS. They also investigated the formation of giant vesicles with increase in $\mathrm{pH}$ and monodispersive vesicles $(50 \mathrm{~nm})$ at $\mathrm{pH}$ 6.5. Importantly, formation of micelles $(25 \mathrm{~nm})$ instead of vesicles has also been demonstrated in the presence of $\mathrm{Ag}^{+}$ions.

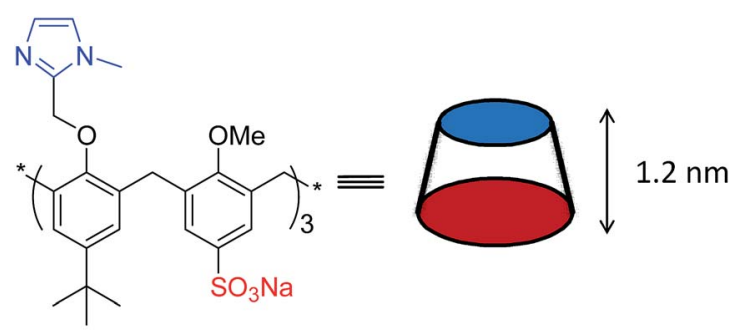

\section{A22}

Fig. 11 Chemical structure and cartoon representation of calixarene derivative $\mathrm{A} 22$.

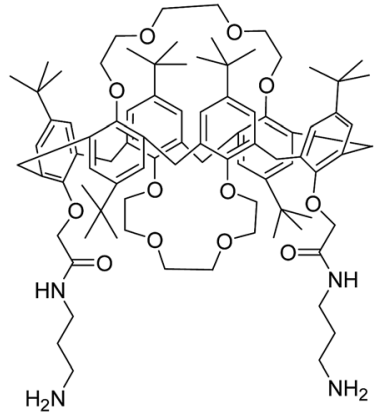

A23

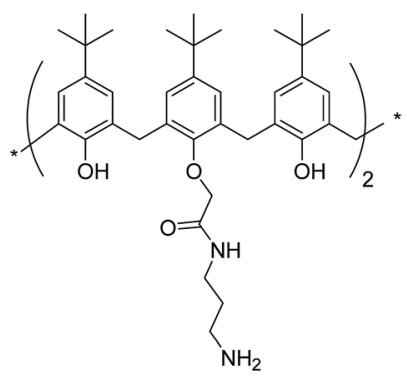

A24
Fig. 12 Chemical structures of calixarene derivatives A23 and A24.
Jiang and co-workers have reported the self-assembling amphiphilic calix[6]crowns A23-A24 (Fig. 12). They studied the self-assembling behavior in water : ethanol $(1: 3) .{ }^{37}$ Authors have confirmed the formation of spherical aggregates in A23 and A24 using TEM and AFM. The hollow nature of vesicles was confirmed by TEM.

Based on the X-ray diffraction pattern, the authors proposed that the vesicles were formed from initially developed layered structures. The transformation of the $\mathbf{A 2 3}$ from vesicles to tubes by changing the composition to water : ethanol $(2: 3)$ was also demonstrated.

\subsection{Curcubituril-based molecules}

Kim and co-workers synthesized ternary complexes A25-A27 (Fig. 13) and demonstrated a remarkable example of a ternary complex A25, that self-assembled into vesicles. ${ }^{38}$ Giant vesicles were formed spontaneously in a mixture of curcubit[8]uril, $n$ alkyl viologen (RV), and dihydroxy naphthalene (DHNp) in water. The ternary complex was formed by charge-transfer interactions between the electron-deficient and electron-rich guest molecules $\left(\mathrm{RV}^{2+}\right.$ and DHNp), inside the hydrophobic cavity of curcubiturils. Vesicles of diameter $20 \mathrm{~nm}$ to $1.2 \mu \mathrm{m}$ were observed in $\mathbf{A} 26\left(\mathrm{R}=\mathrm{C}_{12} \mathrm{H}_{25}\right)$ and $\mathbf{A} 27\left(\mathrm{R}=\mathrm{C}_{16} \mathrm{H}_{33}\right)$. The vesicular structures were characterized by SEM and TEM.

Kim and co-workers reported a new amphiphilic curcubit[6] uril complexes A28-A30 (Fig. 14), that formed vesicles. Due to the strong affinity of these complexes towards polyamines A29A30, the surface of the vesicles can be easily modified through host-guest interactions. ${ }^{39}$

\subsection{Cyclodextrin-based molecules}

Coleman and co-workers synthesized cyclodextrin derivatives A31 and A32 (Fig. 15) that self-assembled to form large vesicles. $^{40}$ Vesicles were observed in THF, and were confirmed by light scattering experiments and solution studies using ${ }^{1} \mathrm{H}$ NMR.

For the first time, Darcy et al. synthesized non-ionic amphiphilic hydroxy alkylated cyclodextrin derivatives, which assembled to bilayer vesicles. ${ }^{\mathbf{4 1}}$ Cyclodextrin derivatives $\mathbf{A 3 3}$ and A34 (Fig. 15), formed the vesicles in water upon sonication, with a diameter ranging from $50-300 \mathrm{~nm}$ as evident from electron micrographs and DLS. Vesicle formation of A33 and A34 was further confirmed by the encapsulation studies of fluorescent dye carboxy-fluorescein in aqueous solution.

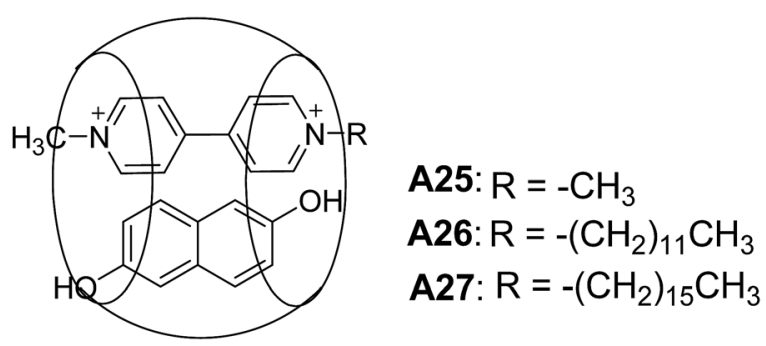

Fig. 13 Chemical structures of curcubituril-derivatives A25-A27 


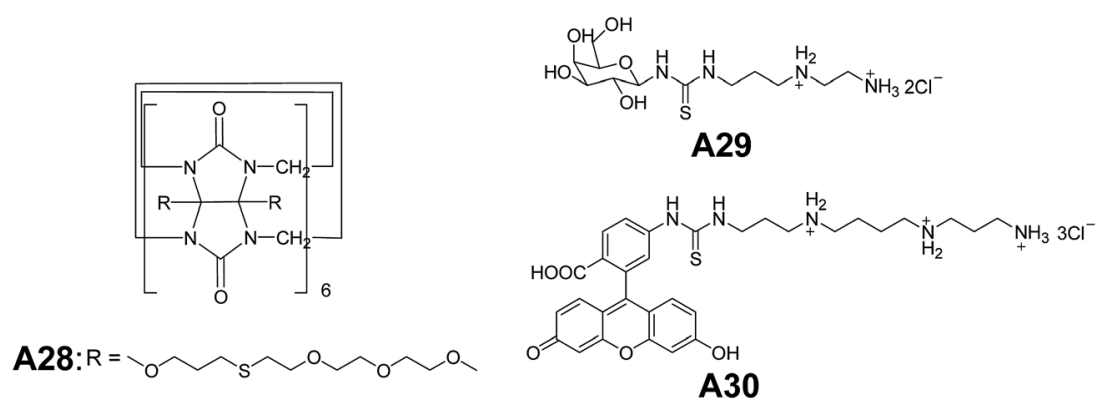

Fig. 14 Chemical structures of curcubituril derivative A28 and polyamines A29-A30.

Chen and co-workers have described a novel strategy to make self-assembled vesicles. ${ }^{42}$ Vesicles were made by sonicating an aqueous solution of cyclodextrin A35, 1-naphthylammonium chloride A36, and sodium bis(2-ethyl-1-hexyl)sulfosuccinate A37 (Fig. 15). These vesicles and their sizes were characterized by TEM and DLS.

Hao and co-workers reported the preparation of vesicles in aqueous solution using $\beta$-cyclodextrin ( $\beta$-CD) complexes with a series of aromatic molecules A39(a-d) (Fig. 16). ${ }^{43}$ Vesicles were

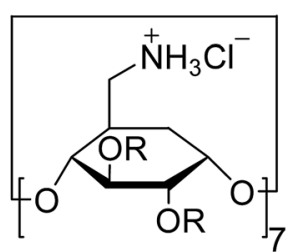

A31: $\mathrm{R}=-\mathrm{C}_{6} \mathrm{H}_{13}$

A32: $\mathrm{R}=-\mathrm{C}_{12} \mathrm{H}_{25}$
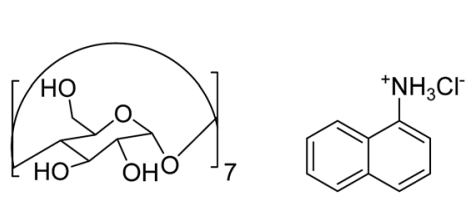

A35

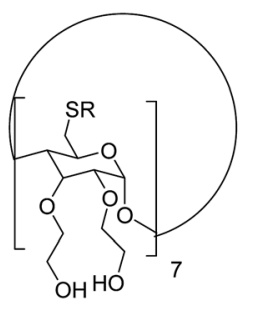

A33: $\mathrm{R}=-\mathrm{C}_{12} \mathrm{H}_{25}$

A34: $\mathrm{R}=-\mathrm{C}_{16} \mathrm{H}_{33}$

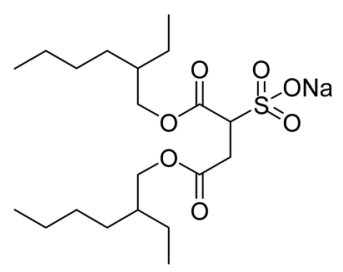

A37
Fig. 15 Chemical structures of cyclodextrin derivatives A31-A34, cyclodextrin, 1-naphthylammonium chloride and sodium bis(2-ethyl1-hexyl)sulfosuccinate A35-A37.

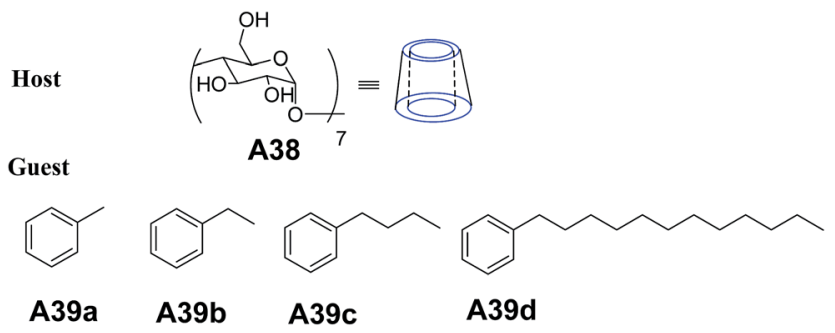

Fig. 16 Chemical structures of cyclodextrin A38, and aromatic guest molecules A39a-d. obtained by injection of hydrophobic guest A39(a-d) in methanol into A38 ( $\beta$-cyclodextrin) in water and were characterized by TEM, AFM and DLS.

\subsection{Fullerene-based molecules}

Tour and co-workers reported the synthesis and the supramolecular assembly of substituted $\mathrm{C}_{60}\left(\mathrm{C}_{60}-N, N\right.$-dimethylpyrrolidinium iodide) $\mathbf{A 4 0 .}^{44}$ Aqueous solution of $\mathbf{A 4 0}$ after ultrasonication followed by filtration, showed vesicles as evident from TEM images. They suggested that the polar groups project towards the polar solvent $\left(\mathrm{H}_{2} \mathrm{O}\right)$ resulting in the formation of vesicles (Fig. 17).

Rod-like structures were also observed when the solution of A40 in water and DMSO was mixed with benzene.

The synthesis of water soluble and stabilized potassium salt of pentaphenyl fullerene $\left(\mathrm{Ph}_{5} \mathrm{C}_{60} \mathrm{~K}\right)$ A41 (Fig. 18) and their bilayer vesicles formation were demonstrated by Zhou and co-workers. ${ }^{45}$ Formation of spherical bilayer vesicles was studied using laser light scattering experiments. The association of $\mathbf{A 4 1}$ in water resulted in the formation of spherical bilayer vesicles. The hollow nature of vesicles was demonstrated by microscopic measurements.

For the first time, the spherical bilayer vesicle formation from a dendritic methano[60]fullerene octadeca-acid $\mathbf{A 4 2}$ (Fig. 18) with a co-surfactant tetradecyltrimethylammonium hydroxide (TTAOH) was reported by Hao and co-workers. ${ }^{46}$ Under normal conditions, TTAOH formed micelles in water, while addition of $\mathbf{A 4 2}$ induced the formation of vesicles. Vesicular structures were characterized by freeze-fracture transmission electron microscopy (FF-TEM) and DLS.

Martín and co-workers investigated the self-assembling behavior of dendro-fullerenes containing triazoles with varying number of carboxylic groups A43-A44 (Fig. 19) in THF and THF : water mixture. ${ }^{47}$ Interestingly, vesicles were observed in $\mathbf{A 4 3}$, but not in the case of $\mathbf{A 4 4}$.

This behavior of $\mathbf{A 4 4}$ was explained based on the fact that the presence of bigger hydrophilic parts in fullerene moiety would prevent the formation of spherical aggregates. Vesicles were characterized by SEM and AFM, and their hollow nature was confirmed by TEM.

\subsection{Polymer-based molecules}

Deming and co-workers reported the synthesis and selfassembly of a series of charged poly(L-lysine)- $b$-poly(L-leucine) 

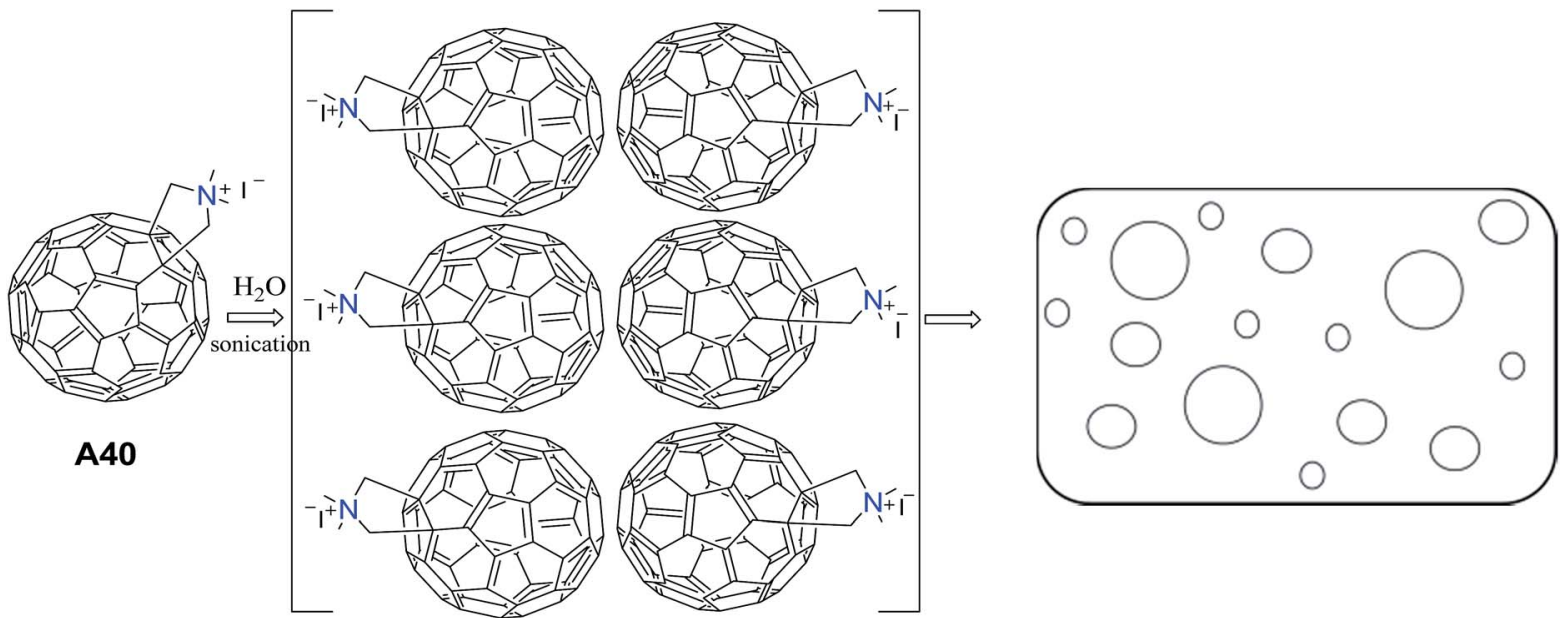

Fig. 17 Vesicles formation by self-assembly of A40.

block copolypeptides A45 (Fig. 20) ( $\mathrm{K}_{x} \mathrm{~L}_{y}: x$ ranged from $20-80$ and $y$ from $10-30$ residues). ${ }^{48}$ Among the charged amphiphilic block co-polypeptides, $\mathbf{A 4 5}\left(\mathrm{K}_{60} \mathrm{~L}_{20}\right)$ showed vesicular assembly in aqueous solution and was characterized by differential interference contrast optical microscopy (DIC), laser scanning confocal microscopy (LSCM) and TEM. Similarly charged

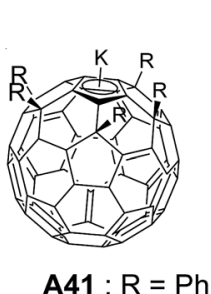

A41 : R = Ph
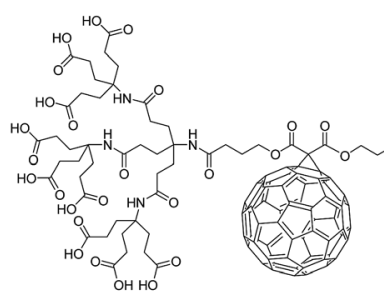

A42

Fig. 18 Chemical structures of penta-substituted fullerene potassium salt A41 and dendritic methano[60]fullerene octadeca-acid A42.

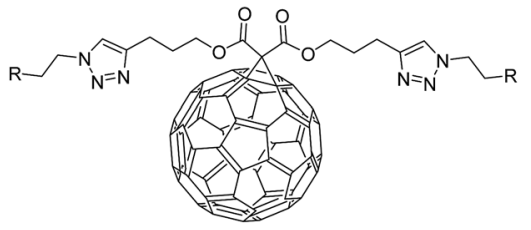

A43

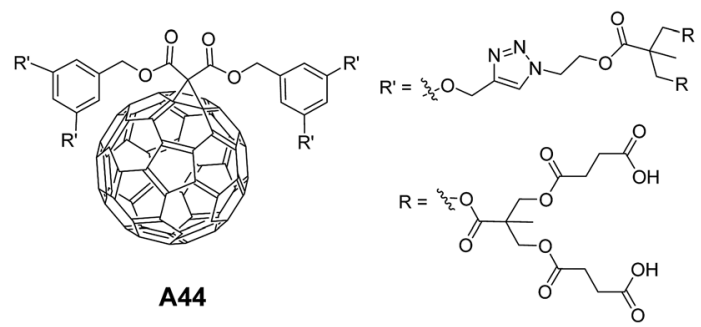

Fig. 19 Chemical structures of amphiphilic dendrofullerenes A43A44. polyarginine segments in block copolypeptides A46 showed vesicular assembly (Fig. 20). ${ }^{49}$

Lee and co-workers reported the synthesis and self-assembly of an amphiphilic rod-coil molecule A47 containing tetra( $p$ phenylene) and oligo(ethylene oxide) along with a mannose terminal unit (Fig. 21) in aqueous solutions. ${ }^{50}$

FE-SEM, and TEM studies of the rod-coil molecule A47 revealed the vesicular assembly. The vesicular assembly was further confirmed by encapsulation studies of fluorescent dye calcein. Authors have also demonstrated the efficient binding of vesicles to FimH adhesin of bacterial type-1 pili in Escherichia coli $(E$. coli), which is attributed to the presence of mannose units on the exterior of the vesicles.

Hest and co-workers reported an unprecedented vesicular assembly from amphiphilic polystyrene-block-poly(acrylic acid) (PS- $b$-PAA) containing azide groups at periphery $\mathbf{A 4 8}$ (Fig. 22). ${ }^{51}$ The vesicular structures were obtained on slow addition of water to the solution of block copolymer in dioxane followed by

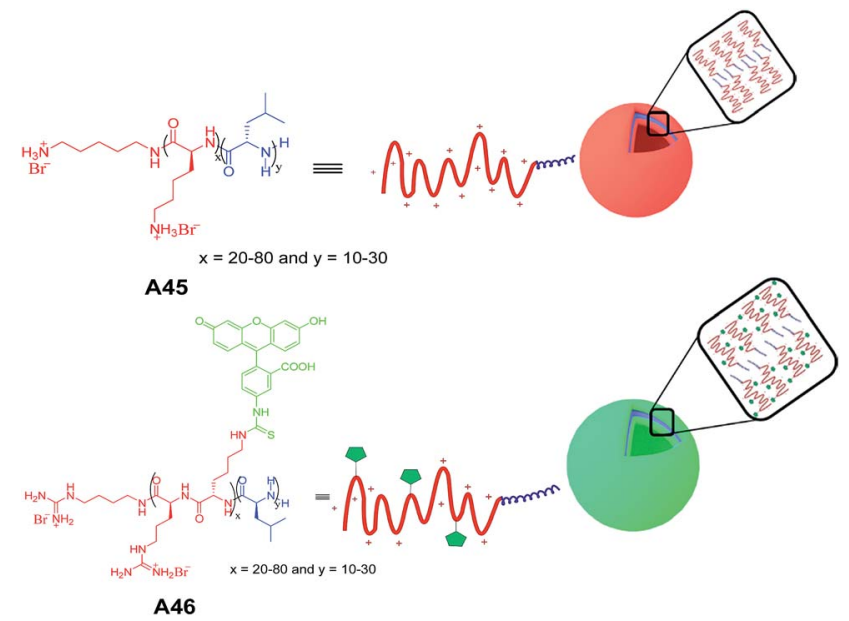

Fig. 20 Chemical structures of charged amphiphilic block copolypeptides A45-A46 and schematic diagram of proposed self-assembly of vesicles. 

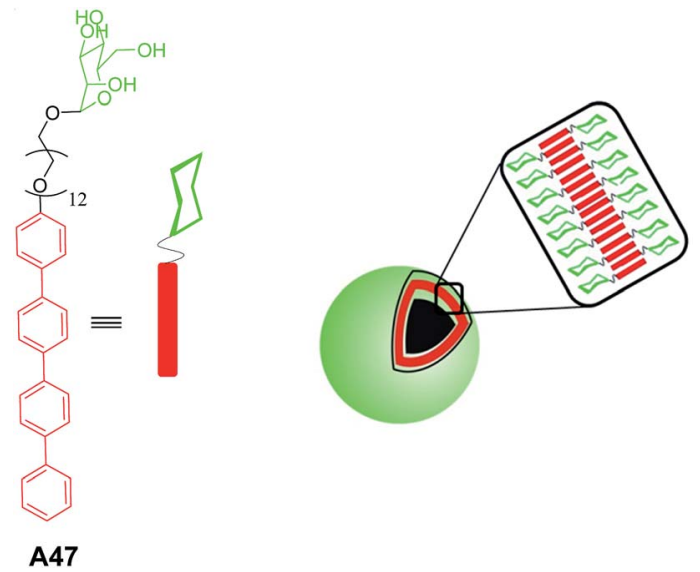

Fig. 21 Chemical structure of amphiphilic rod-coil molecule A47 and schematic representation of self-assembly.

the removal of organic solvent by extensive dialysis against water. Interestingly, when azide polymersomes were further functionalized using 'click' reaction to yield A49 (Fig. 22), no change in the morphology was observed.

Schlaad and co-workers studied the aggregation behavior of polybutadiene $_{165}$-block-poly(L-lysine $)_{88} \quad\left(\mathrm{~PB}_{165}-b\right.$ - PLLys $\left._{88}\right) \quad$ A50 (Fig. 23) in saline solution. ${ }^{52}$ Larger vesicles at $\mathrm{pH} 7.0$ and smaller vesicles at $\mathrm{pH} 10.3$ were obtained as characterized by TEM and DLS. Change in size of vesicles with $\mathrm{pH}$ is due to colloidal stabilization in basic solutions.

Meier and co-workers synthesized and studied the self-assembly of a poly(2-methyloxazoline)-block-poly(dimethylsiloxane)-blockpoly(2-methyloxazoline),

(PMOXA-PDMS-PMOXA) triblock

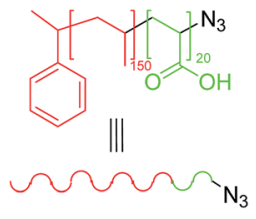

A48

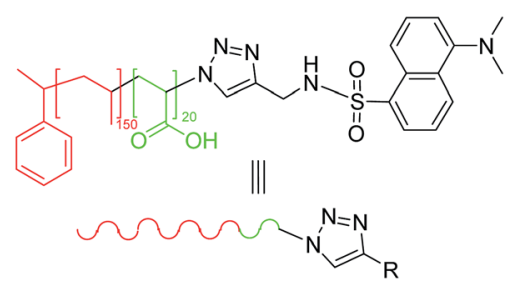

A49
Fig. 22 Chemical structures of amphiphilic block copolymer with peripheral azide moieties A48 and 'click' modified moiety A49.

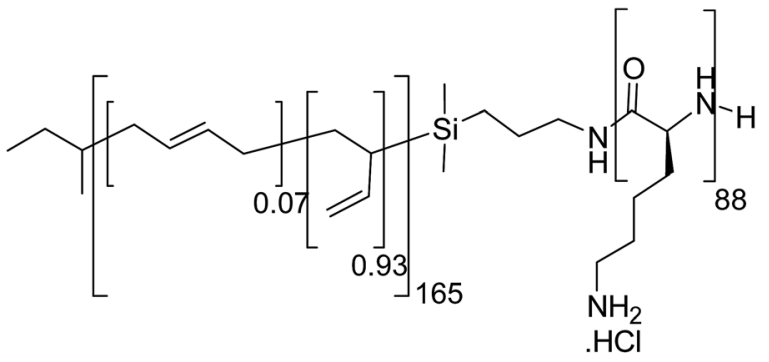

A50

Fig. 23 Chemical structure of $\mathrm{PB}_{165}-b-\mathrm{PLLys}_{88} \mathrm{~A} 50$

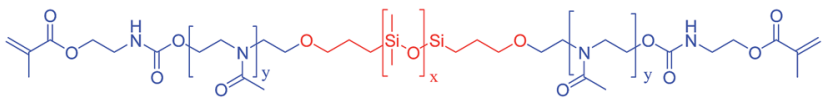

A51 (PMOXA-PDMS-PMOXA)

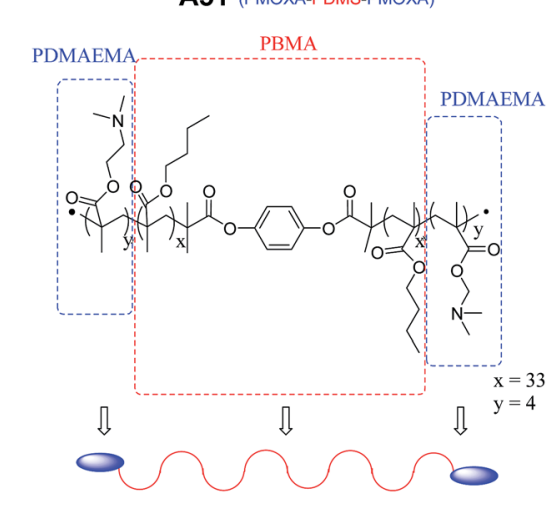

Hydrophilic

Hydrophobic Part

Hydrophilic

A52

Fig. 24 Chemical structures of PMOXA-PDMS-PMOXA triblock copolymer A51 and PDMAEMA-PBMA-PDMAEMA amphiphilic triblock copolymer A52.

copolymer A51 (Fig. 24) carrying polymerizable methacrylate groups at both the ends. ${ }^{53}$ The vesicular structures observed from polymer, PMOXA-PDMS-PMOXA A51 and their polymerized counterparts in aqueous solution were characterized by SEM, TEM, DLS and static light scattering (SLS) techniques. The authors also reported vesicles from similar type of charged triblock copolymer poly(2,2-dimethylaminoethyl methacrylate)-block-poly(n-butyl methacrylate)-block-poly(2,2-dimethylaminoethyl methacrylate) (PDMAEMA-PBMA-PDMAEMA) A52 (Fig. 24). ${ }^{54}$

Ghosh et al. reported self-assembly of the copolymer A53 (Fig. 25) in aqueous solution. ${ }^{55}$ This polymer contains methacrylate-type hydrophobic and methacrylamide-type hydrophilic repeat units. The vesicular structures were

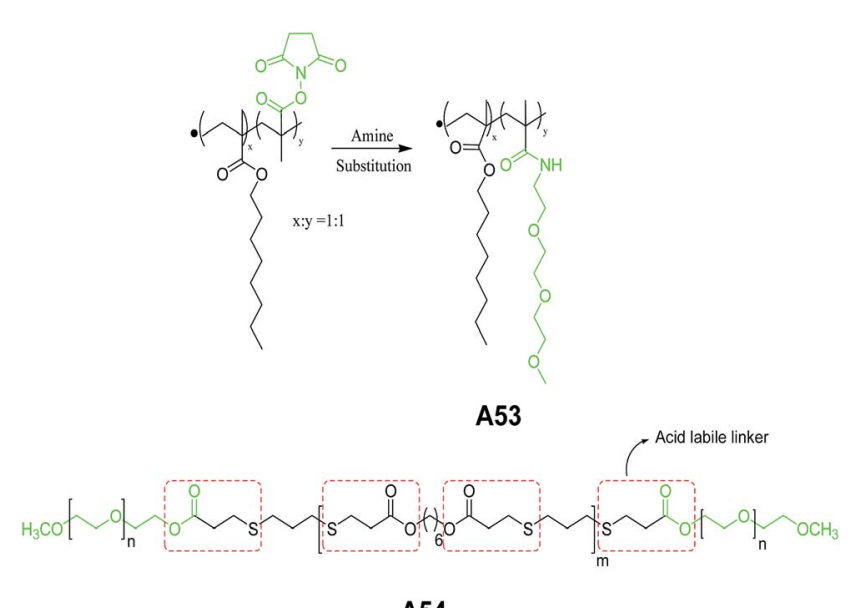

A54

Fig. 25 Chemical structures of amphiphilic copolymer A53 and amphiphilic triblock copolymer A54. 
characterized by TEM and dye encapsulation studies. The authors also demonstrated the morphological transition of A53 from vesicles to micelle aggregates above its critical morphology transition temperature (CMTT). In the succeeding year, same group demonstrated the $\mathrm{pH}$-responsive vesicular assembly with acid-labile amphiphilic triblock copolymer A54 (Fig. 25). ${ }^{56}$

\subsection{Peptide-based molecules}

Bergeron and co-workers investigated the self-assembling properties of a series of peptide-based molecules A55-A62 (Fig. 26). ${ }^{57}$ Among all diketopiperazine derivatives, microcapsules were only observed from the basic solutions of tetrapeptides derived from L-aspartic acid diketopiperazines A57 and A58, when acidified to $\mathrm{pH}=2.4$. Based on the results from $\mathbf{A 5 7}$ and A58, authors have established that methylene chain length have an impact on the morphology. The authors have also shown that even small structural alteration can cause the drastic change in the physiochemical properties of these tetrapeptides.

Gazit and co-workers studied the self-assembly of diphenylalanine dipeptide (Phe-Phe, FF) A63 (Fig. 27), the core motif of Alzheimer's $\beta$-amyloid polypeptide. ${ }^{58}$ An interesting morphological transition was observed when phenyl glycine (Phg) was used instead of Phe. They have demonstrated that Phe-Phe A63 self-assembled into nanotubes, whereas Phg-Phg $\mathbf{A 6 4}$ formed spherical vesicles under similar conditions, and is attributed to constrained rotational freedom and higher steric hindrances of Phg in A64. Further, the morphological transitions from nanotube to vesicle was observed when the dipeptide Phe-Phe was linked with a cysteine residue at the N-terminus A65 (Fig. 27). These fascinating results were explained by a model based on hydrogen bonding, aromatic $\pi-\pi$ interactions and the disulfide bridge formation.

In the later years, Gazit, Verma and co-workers explored the use of molecules with the triskelial architecture (Fig. 28). ${ }^{59}$ They designed and synthesized tripodal triskelion ditryptophan conjugate $\mathbf{A 6 6}$ that self-assembled into spherical nanostructures in methanol : water mixture. $\mathrm{MM}^{+}$-optimized structure confirmed the existence of slight curvature in the triskelial architecture, which coupled with $\pi-\pi$ interactions of indole moieties, led to the formation of vesicular structures. They also demonstrated the guest entrapment in triskelion nanocages.

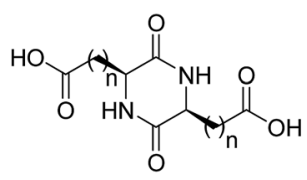<smiles>[R]C(NC(=O)C[C@H]1NC(=O)[C@H]([Te]C(=O)NC([R])([R])C(=O)O)NC1=O)C(=O)O</smiles>

A55: $\mathrm{n}=1$ A56: $n=2$

$$
\begin{aligned}
& \text { A57: } \mathrm{n}=1, \mathrm{R}=\mathrm{CH}_{2} \mathrm{Ph}, \mathrm{R}^{\prime}=\mathrm{H} \\
& \text { A58: } \mathrm{n}=1, \mathrm{R}=\mathrm{H}, \mathrm{R}^{\prime}=\mathrm{CH}_{2} \mathrm{Ph} \\
& \text { A59: } \mathrm{n}=2, \mathrm{R}=\mathrm{H}, \mathrm{R}^{\prime}=\mathrm{CH}_{2} \mathrm{Ph} \\
& \text { A60: } \mathrm{n}=1, \mathrm{R}=\mathrm{H}, \mathrm{R}^{\prime}=\mathrm{H} \\
& \text { A61: } \mathrm{n}=1, \mathrm{R}=\mathrm{H}, \mathrm{R}^{\prime}=\mathrm{CH}_{3} \\
& \text { A62: } \mathrm{n}=1, \mathrm{R}=\mathrm{H}, \mathrm{R}^{\prime}=\mathrm{CH}\left(\mathrm{CH}_{3}\right)_{2}
\end{aligned}
$$

Fig. 26 Chemical structures of diketopiperazine based peptidic molecules A55-A62.
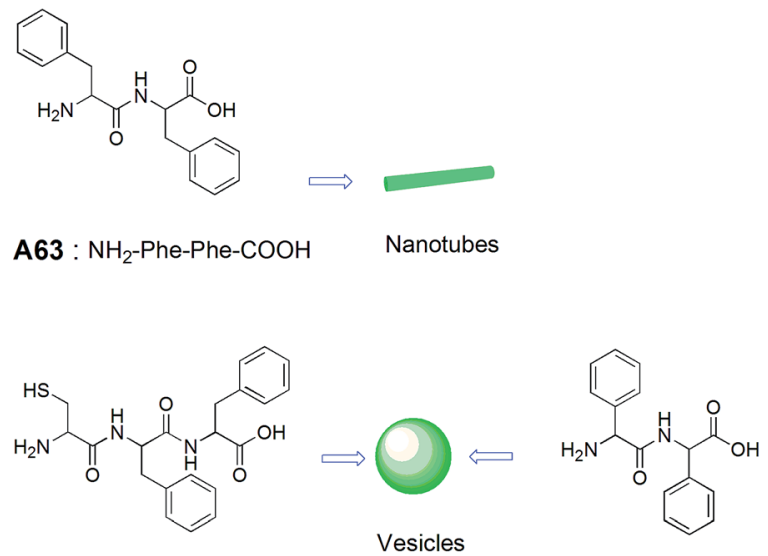

A65: $\mathrm{NH}_{2}$-Cys-Phe-Phe- $\mathrm{COOH}$

A64: $\mathrm{NH}_{2}$-Phg-Phg- $\mathrm{COOH}$

Fig. 27 A model for alternative assembly of tubular and spherical peptide nanostructures.

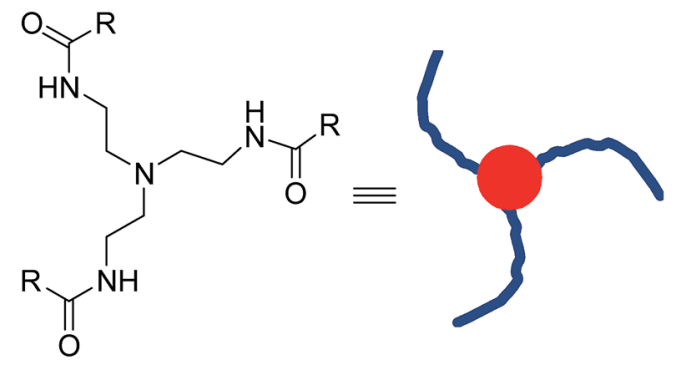

A66: $R=$ Trp-Trp

Fig. 28 Molecular structure of a tripodal dipeptide derivative A66.

In an earlier work, Gokel and co-workers designed and synthesized a variety of indole-based lipidated molecules that formed vesicular assembly. ${ }^{60}$

Lee and co-workers synthesized and studied the selfassembly of peptides A67-A70 (Fig. 29), composed of a polyproline and a hydrophilic cell-penetrating peptide Tat coil. ${ }^{61}$ Vesicular structures from A67-A70 were characterized by TEM, and authors hypothesized that the rigidity of the polyproline helix allowed the separation of hydrophobic rod and the hydrophilic peptide coil, which helped to form self-assembled nanocapsules. These nanocapsules were demonstrated to cross the membrane barrier of the cell.

In the later years, the morphological transition from nanotubes to vesicles were reported by $\mathrm{Li}$ and co-workers. ${ }^{62}$ They have observed the self-assembled nanotubes of cationic dipeptide $\mathrm{NH}_{2}-\mathrm{Phe}-\mathrm{Phe}-\mathrm{NH}_{2} \cdot \mathrm{HCl} \mathbf{A 7 1}$ at physiological $\mathrm{pH}=7.2$ that transformed into vesicles upon dilution (Fig. 29). The authors also demonstrated that these self-assembled nanotubes could be used to deliver the oligonucleotides to interior of the cell and hence, can be used as drug delivery vehicles.

Alfonso and Luis et al., in 2010, synthesized and studied a series of pseudopeptidic macrocycles A72-A78 (Fig. 30) both in solid (SEM, TEM, FTIR) and solution (NMR, UV, CD, FTIR) 

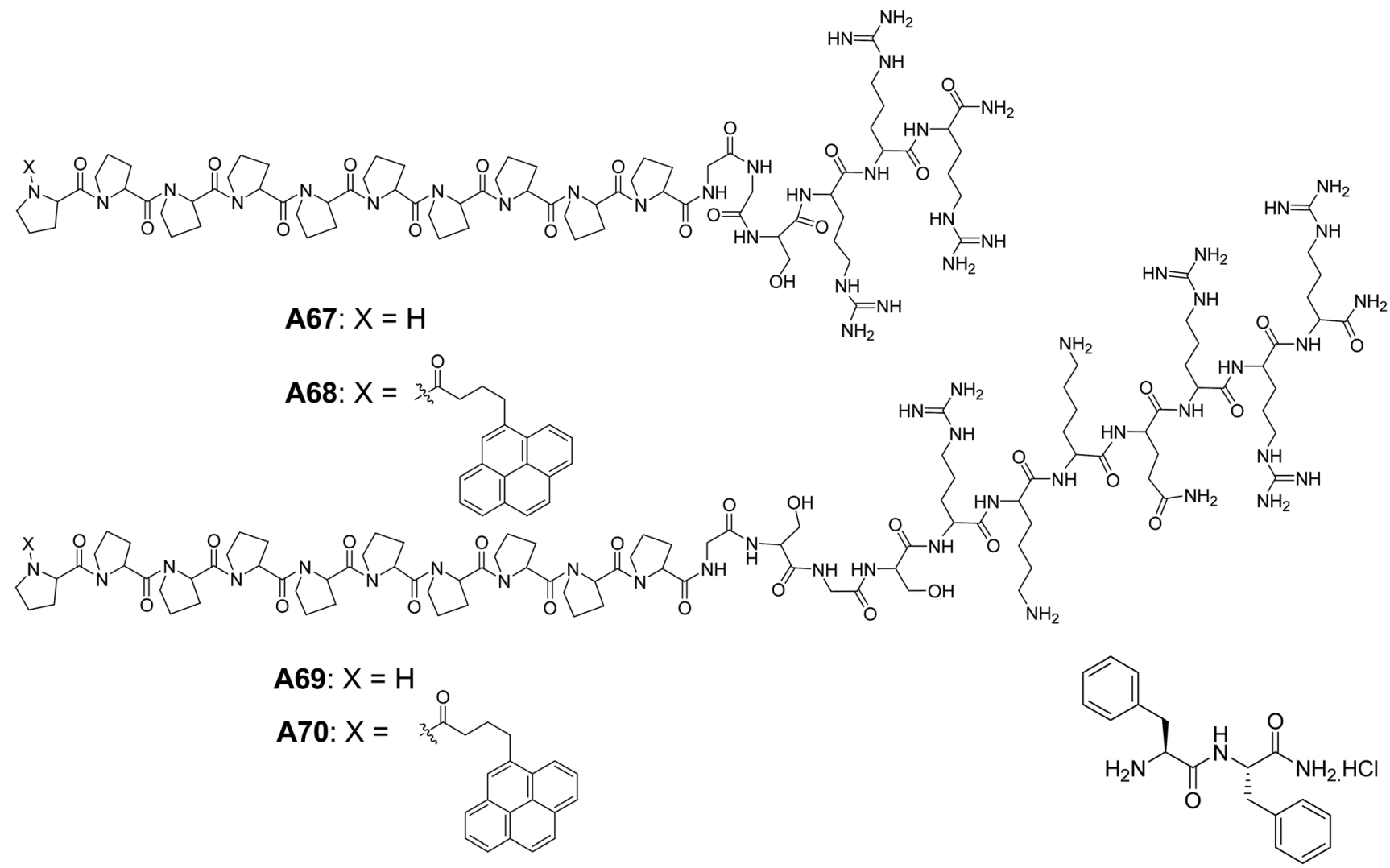

A71 : $\mathrm{NH}_{2}-\mathrm{Phe}-\mathrm{Phe}-\mathrm{NH}_{2} \cdot \mathrm{HC}$

Fig. 29 Chemical structures of peptide rod-coil building blocks A67-A70 and cationic dipeptide A71.

states. ${ }^{63}$ Samples were prepared in methanol : chloroform $(9: 1)$ and compounds A72-A77 self-assembled into fibers.

Interestingly, when benzyl groups were introduced as side chains, the meta derivative of cyclic peptide $\mathbf{A 7 8}$ self-assembled to form the spherical structures with diameters ranging from $0.5-3 \mu \mathrm{m}$. From these observations, the authors hypothesized that the vesicles were formed due to the synergistic action of $\pi-$ $\pi$ interactions and H-bonding between amide bonds. The hollow nature of the vesicles from $\mathbf{A 7 8}$ was confirmed by TEM analysis.

Banerjee and co-workers reported the self-assembling behavior of dipeptides A79-A81 (Fig. 31) containing glutamic acid residues at the C-terminus. ${ }^{64}$ These dipeptides A79-A81

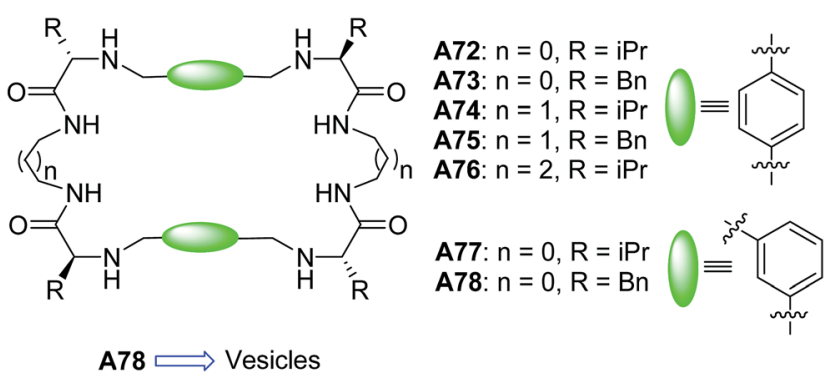

Fig. 30 Chemical structures of pseudopeptidic molecules A72-A78. formed multi-vesicular structures in water and were stable over a wide range of $\mathrm{pH}$. However, rupturing of vesicles in presence of calcium ions revealed their sensitivity towards these metal ions.

The authors have also demonstrated the encapsulation of anti-cancer drug and their release in the presence of calcium ions. Transport of cyclic adenosine monophosphate (cAM) across the cell membrane by multi-vesicular structures was reported, without altering their biological functions.

Lim and co-workers designed and synthesized a series of structurally similar cyclic and linear peptides A82-A83 (Fig. 32 and 33) to study the effect of peptide topology on the self-<smiles>[R]C(N)C(=O)N[C@@H](CCC(=O)O)C(=O)O</smiles>

$$
\begin{aligned}
& \text { For peptide A79: } \mathrm{R}=\mathrm{CH}\left(\mathrm{CH}_{3}\right)_{2} \\
& \text { For peptide A80: } \mathrm{R}=\mathrm{CH}_{2} \mathrm{CH}\left(\mathrm{CH}_{3}\right)_{2} \\
& \text { For peptide A81: } \mathrm{R}=\mathrm{CH}_{2} \mathrm{CH}_{2} \mathrm{CH}_{3}
\end{aligned}
$$




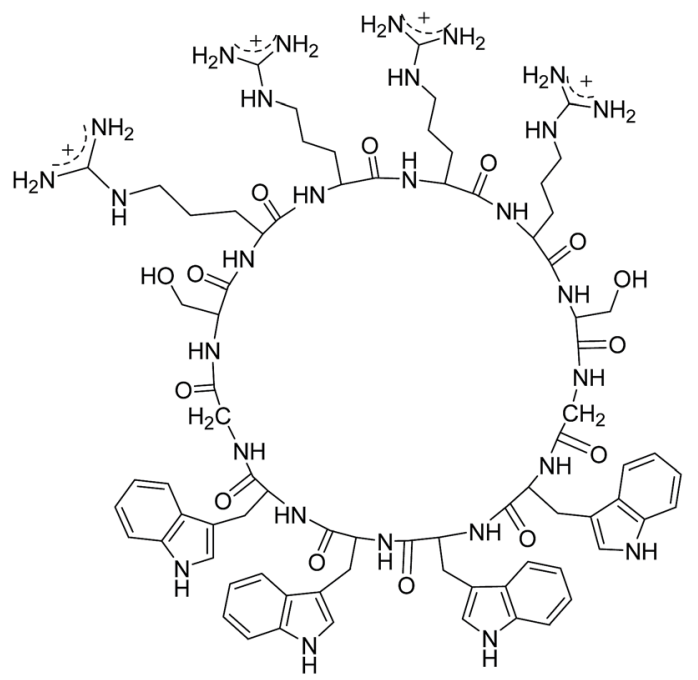

A82 $\Longrightarrow$ Vesicles

Fig. 32 Chemical structure of peptide based cyclic molecule A82.

assembly. ${ }^{65}$ Cyclic peptide $\mathbf{A 8 2}$ formed homogeneous population of spherical assembly because of their constrained structure, whereas linear peptide $\mathbf{A 8 3}$ (Fig. 33) showed irregular nano-aggregates.

Pramanik and co-workers synthesized a set of tripeptides A84-A85 (Fig. 33). The C-termini of the peptides were protected with methyl ester of $m$-aminobenzoic acid and $\mathrm{N}$-termini with Boc group. The self-assembly of these tripeptides were studied in different solvents. ${ }^{66}$ Vesicular assembly was observed from peptides A84 and A85 in methanol. They reported a variety of supramolecular structures from these peptides such as

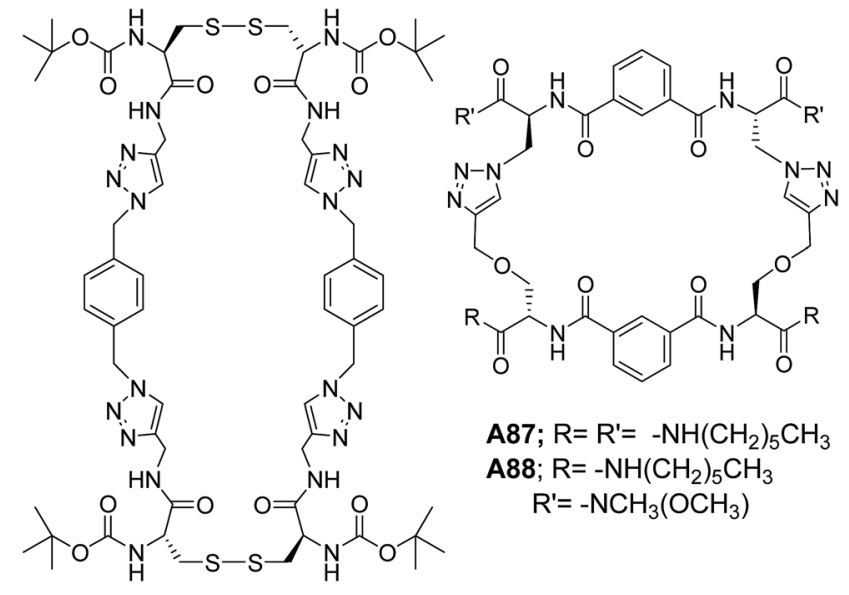

A86

Fig. 34 Chemical structures of peptide-triazole hybrid macrocycles A86-A88.

nanotubes, giant microvesicles and macroporous vesicles depending upon the polarity of solvent system employed. These nanostructures were characterized by several microscopic techniques.

Our group has designed and synthesized a series of selfassembling peptide-triazole hybrid macrocycles A86-A88 (Fig. 34). The disulphide-based $2+2$ macrocycle $\mathbf{A 8 6}$ selfassembled to form the vesicles, while the smaller macrocycle $(1+1)$ showed amyloid-type assembly. ${ }^{67}$

The ditriazole macrocycles A87-A88 (Fig. 34) also showed the vesicular morphology. ${ }^{68}$

We further extended our investigation to another set of triazolophanes A89-A91 (Fig. 35) in order to gain a deep insight<smiles>N=C(N)NCCC[C@@H](N)C(=O)NC(CCCNC(N)=[NH2+])C(=O)NC(CCCNC(N)=[NH2+])C(=O)NC(CCCNC(N)=[NH2+])C(=O)NCC(=O)NC(CO)C(=O)NC(Cc1c[nH]c2ccccc12)C(=O)NC(Cc1c[nH]c2ccccc12)C(=O)NC(Cc1c[nH]c2ccccc12)C(=O)NC(Cc1c[nH]c2ccccc12)C(=O)NC(CO)C(=O)NCC(=O)[O-]</smiles>

\section{A83}<smiles>[R2][C@H](NC(=O)C(C)(C)NC(=O)[C@@H]([R7])NC(=O)OC(C)(C)C)C(=O)Nc1cccc(C(=O)OC)c1</smiles>

Peptide A84: $\mathrm{R}_{1}=\mathrm{CH}_{2} \mathrm{CH}\left(\mathrm{CH}_{3}\right)_{2}, \mathrm{R}_{2}=-\mathrm{CH}\left(\mathrm{CH}_{3}\right)_{2}$

Peptide A85: $\mathrm{R}_{1}=\mathrm{CH}_{2} \mathrm{C}_{6} \mathrm{H}_{5}, \mathrm{R}_{2}=-\mathrm{CH}\left(\mathrm{CH}_{3}\right)_{2}$

Fig. 33 Chemical structures of peptide based linear molecules A83-A85 


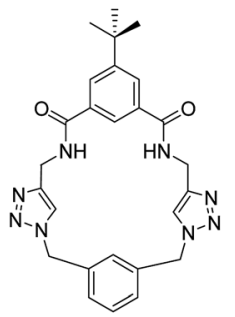

A89

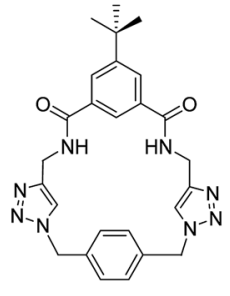

A90

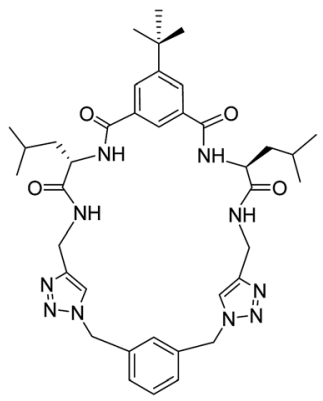

A91

Fig. 35 Chemical structures of triazolophanes A89-A91.

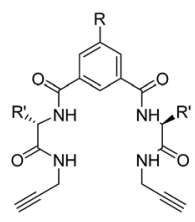

A92: $\mathrm{R}=\mathrm{H}, \mathrm{R}^{\prime}=\mathrm{CH}_{2} \mathrm{CH}\left(\mathrm{CH}_{3}\right)_{2}$

A93: $\mathrm{R}=\mathrm{C}\left(\mathrm{CH}_{3}\right)_{3}, \mathrm{R}^{\prime}=\mathrm{CH}_{2} \mathrm{CH}\left(\mathrm{CH}_{3}\right)_{2}$

Fig. 36 Chemical structures of acyclic hybrid peptide molecules A92A95.

into the mechanism of vesicular assembly. Interestingly, the concentration dependent morphological analysis showed the hierarchical mechanism of vesicular self-assembly. ${ }^{69}$

A detailed ultramicroscopic analysis and crystallographic investigation supported the formation of vesicles through the intermediacy of toroids.

Recently, we have reported the vesicular self-assembly from a series of acyclic hybrid peptide molecules A92-A94 (Fig. 36). The control compound A95 (Fig. 36), which structurally resembles half of the molecules A92-A94, showed the tubular morphology. ${ }^{70}$ This demonstrated that the topological curvature in A92-A94 complemented with extensive interactions assisted the formation of vesicles, while the tubular morphology in $\mathbf{A 9 5}$ is attributed to the lack of curvature.

Our group has also reported the vesicular self-assembled structures from an interesting class of tryptophan (Trp) containing peptide-based systems A96-A98 (Fig. 37). ${ }^{71}$ The hollow nature of vesicles was confirmed by dye encapsulation as monitored through confocal microscopy and steady-state fluorescence data. The vesicles formed by $\mathbf{A 9 7}$ showed an amazing tendency to penetrate the cell-membrane underscoring the importance of Trp units. ${ }^{71 a}$

\subsection{Dendrimer-based molecules}

Wang and co-workers have reported soft vesicles from diblock codendrimer A99 (Fig. 38), which is composed of two blocks of monodendrons. ${ }^{72}$ One monodendron is poly(benzyl ether) (g3PBE) based on 3,5-dihydroxybenzyl alcohol, while the other is aliphatic polyether monodendron based on methallyl dichloride (g3-PMDC). The self-assembling studies were carried out in

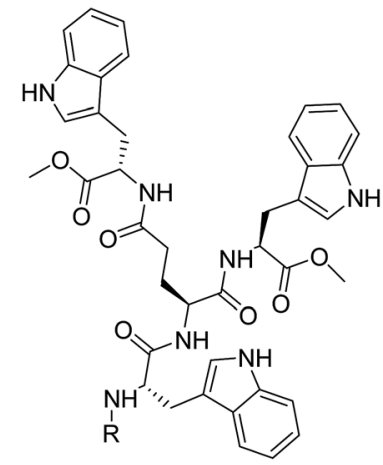

A96: $R=B o c$ A97: $\mathrm{R}=\mathrm{H}$

Fig. 37 Chemical structures of tryptophan-based compounds A96A98.

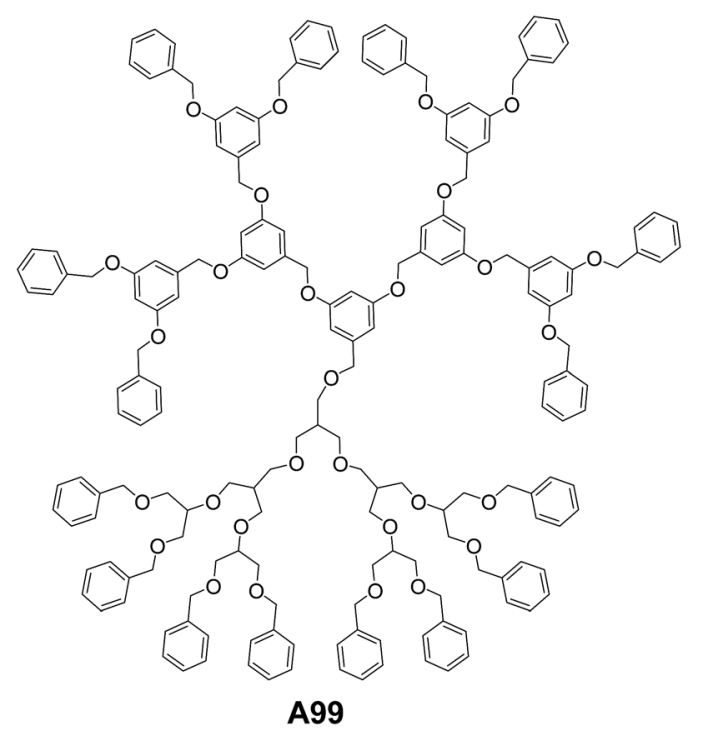

Fig. 38 Chemical structure of dendrimer A99.

1:1 solvent mixture of tetrahydrofuran : diisopropylether. Vesicular aggregates were observed using tapping mode AFM imaging and the average sizes reported were about $150 \mathrm{~nm}$.

Percec and co-workers studied the preparation and properties of dendrimersomes from a library of Janus-dendrimers A100-A108 (Fig. 39), which were composed of two distinct building blocks. ${ }^{73}$ The vesicular structures were observed, when the dilute solutions of Janus-dendrimers in THF : EtOH were dispersed in water.

Our group has designed and synthesized a series of lysine amino acid-based dendrons A109-A110 (Fig. 40). These dendrons showed vesicular assembly as evident from SEM, TEM and AFM microscopic images. ${ }^{74}$ The increase in concentration of these dendrons led to the formation of gels with fibril morphology. These fibres were formed as a result of fusion of the vesicles as demonstrated by TEM and AFM images. 


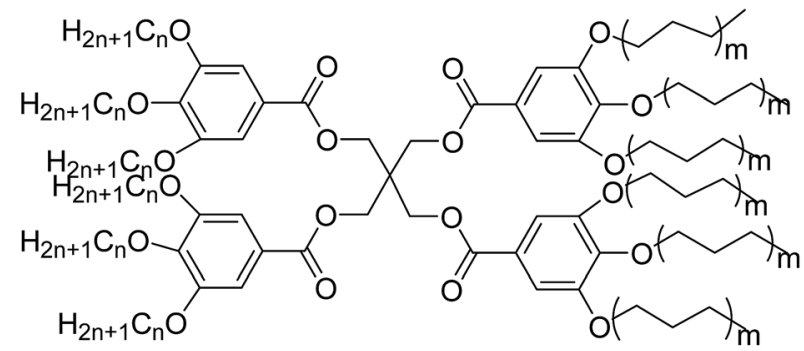

$\mathrm{n}=6,12,16$
A100: $n=6, m=0$
A103: $\mathrm{n}=12, \mathrm{~m}=0$
A106: $n=16, m=0$
A101: $\mathrm{n}=6, \mathrm{~m}=1 \quad$ A104: $\mathrm{n}=12, \mathrm{~m}=1 \quad$ A107: $\mathrm{n}=16, \mathrm{~m}=1$
A102: $n=6, m=2 \quad$ A105: $n=12, m=2 \quad$ A108: $n=16, m=2$

Fig. 39 Chemical structures of Janus-dendrimers A100-A108.

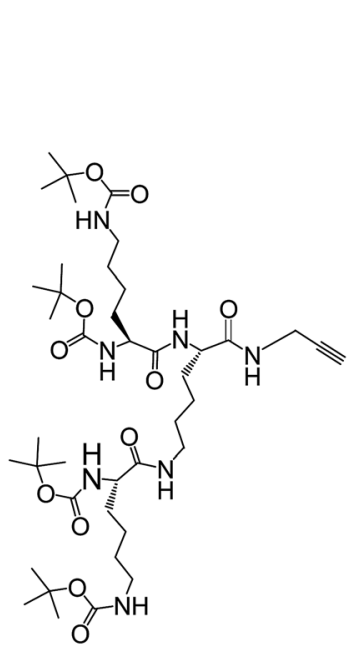

A109

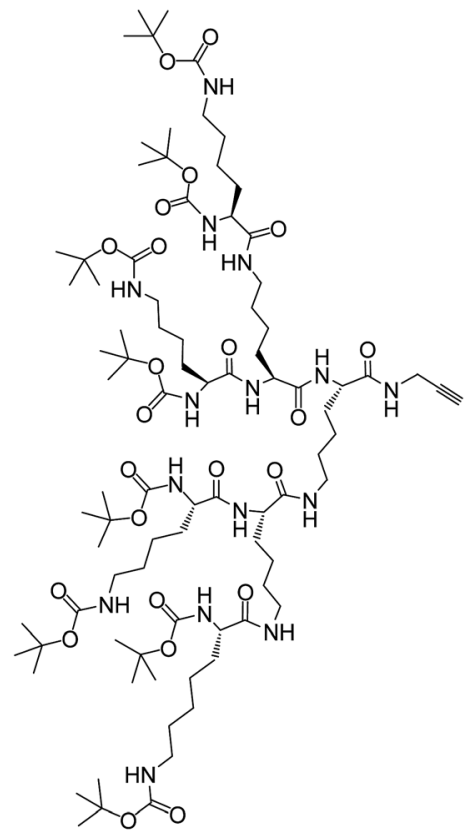

A110

Fig. 40 Chemical structures of lysine amino acid-based dendrons A109-A110.

We have also reported the triazole containing urea-cored peptide dendrimers A111-A113 (Fig. 41). These dendrimers self-assembled to form the vesicles of diameter $0.5-2.0 \mu \mathrm{M}$ as evident from SEM, TEM and AFM. ${ }^{75}$ The molecular dynamics simulation further supported the vesicular assembly of these dendrimers. Interestingly, the corresponding non-triazole ureacored dendrimers did not form the vesicular assembly, rather fibril morphology was obtained. This highlights the key role of triazole units in governing the vesicular self-assembly.

\subsection{Aromatic lipidated molecules}

Ajayaghosh and co-workers have reported the vesicular structures from an unprecedented self-assembly of tripodal<smiles>COC(=O)CCC(NC(=O)Cn1cc(CNC(=O)NCc2cn(CC(=O)NC(CCC(=O)OC)C(=O)OC)nn2)nn1)C(=O)OC</smiles>

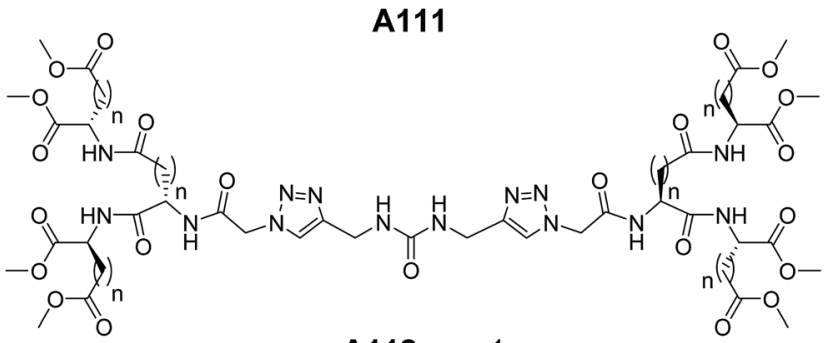

A112: $n=1$

A113: $n=2$

Fig. 41 Chemical structures of urea-triazole cored peptide dendrimers A111-A113.

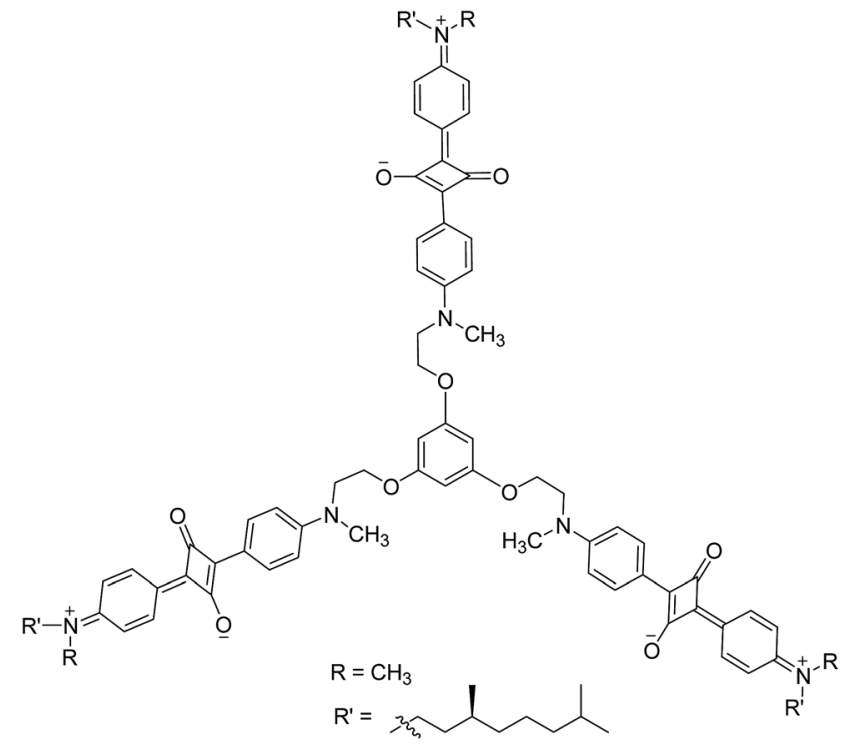

A114

Fig. 42 Chemical structure of squaraine-based molecule A114

squaraine dye in acetonitrile $\mathbf{A 1 1 4}$ (Fig. 42) ${ }^{76}$ For the first time, authors reported the vesicular assembly of squaraine-based compound. The hollow nature of the spherical vesicles was confirmed by TEM images, which clearly showed the contrast between the periphery and inner part of the sphere. The authors demonstrated the transformation of hollow spherical structures to helices upon binding with $\mathrm{Ca}^{2+}$ or $\mathrm{Mg}^{2+}$. This was the first proposed example of cation induced transformation from spherical assemblies to helical structures. In the same year, authors reported the vesicular assembly from short oligo( $p$ phenyleneethynylene) molecules A115-A116 (Fig. 43) in decane. ${ }^{77}$ Interestingly, the increase in concentration induced the fusion of vesicles leading to the formation of gel. 
<smiles>[R]Oc1cc(C)c([R20])cc1C#Cc1cc([R20])c(C#Cc2cc([R20])c(C)cc2[R20])cc1[R20]</smiles>

A115 : $\mathrm{R}=\mathrm{C}_{12} \mathrm{H}_{25}$<smiles>[R20]Oc1cc(C#Cc2cc([R20])c(C#Cc3cc(O[R20])c(CO)cc3[R20])cc2[R20])c([R2])cc1CO</smiles>

A116: $\mathrm{R}=\mathrm{C}_{12} \mathrm{H}_{25}$

Fig. 43 Chemical structures of oligo(p-phenyleneethynylene) molecules A115-A116.

$\mathrm{Li}$ and co-workers synthesized and studied the vesicular selfassembly from lipidated aromatic derivatives A117-A119 (Fig. 44) by incorporating aromatic residues for $\pi-\pi$ stacking, amide moieties for intermolecular hydrogen bonding and van der Waals interaction inducing long aliphatic chains. ${ }^{78}$ The selfassembly of A117-A119 was studied in hot methanol, due to their low solubility in methanol at room temperature. The vesicles were characterized by SEM, TEM and AFM and their sizes were found to be $1.2-5 \mu \mathrm{m}$. The hollow nature of vesicles was confirmed by TEM and encapsulation studies using fluorescent dye Rhodamine B.

$\mathrm{Li}$ and co-workers also reported a series of lipidated molecules A120-A121 and studied their self-assembly (Fig. 45)..$^{79}$ The lipidated cyclophane A120 formed spherical vesicles in chloroform and were characterized by SEM, TEM and AFM. Based on the diameters of the macrocyclic framework and vesicles, authors have proposed that vesicles are formed as a result of stacking of macrocycles.

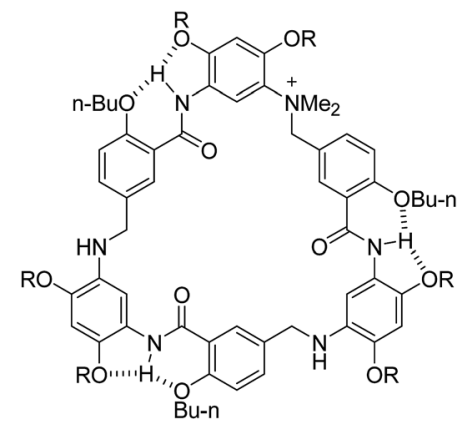

A120 : $\mathrm{R}=\mathrm{n}-\mathrm{C}_{8} \mathrm{H} 17$

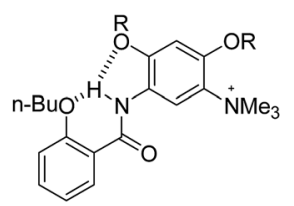

A121 : $\mathrm{R}=\mathrm{n}-\mathrm{C}_{8} \mathrm{H} 17$

Fig. 45 Chemical structures of lipidated aromatic derivatives A120A121.

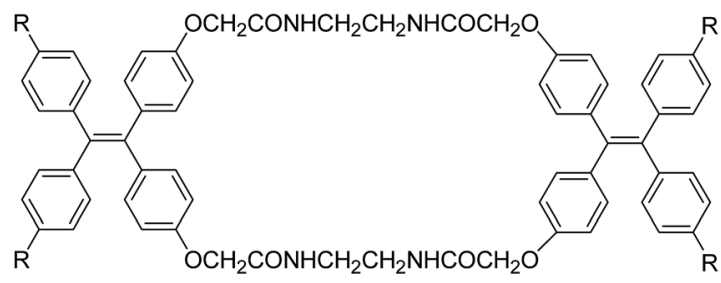

A122 : $\mathrm{R}=\mathrm{H}$

A123: $\mathrm{R}=\mathrm{OC}_{10} \mathrm{H}_{21}$

Fig. 46 Chemical structures of tetraphenylethylene-based amide macrocycles A122-A123.

Interestingly, A121 did not form the vesicular aggregates in chloroform which indicated the important role of the cooperativity in stacking of aromatic segments of A120.

Zheng and co-workers reported the synthesis and selfassembly of tetraphenylethylene-based amide macrocycles A122-A123 (Fig. 46). ${ }^{80}$ The self-assembly of A122 and $\mathbf{A 1 2 3}$ were studied in different ratios of $\mathrm{H}_{2} \mathrm{O}$ : THF mixture.

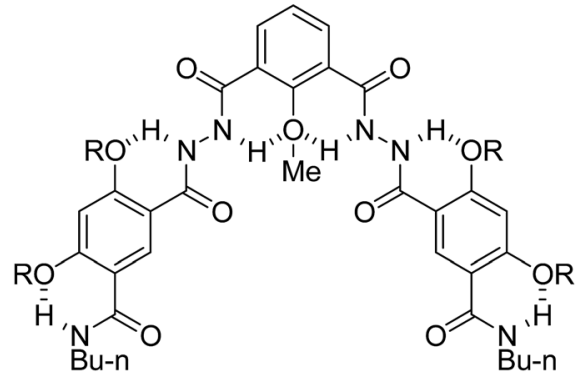

A117

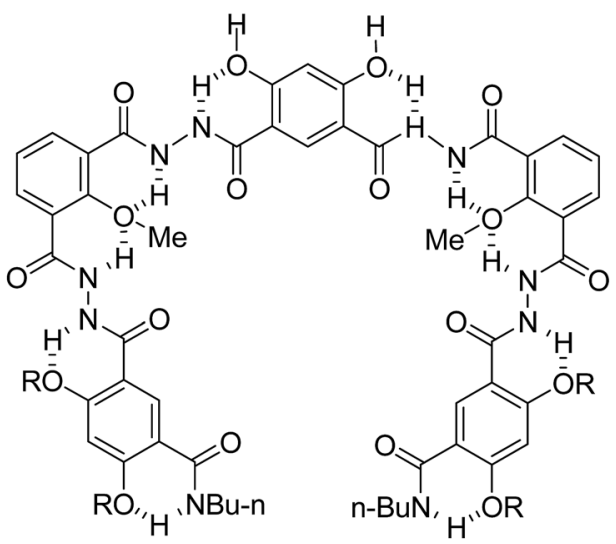

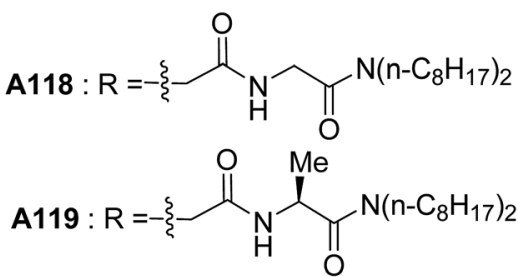

Fig. 44 Chemical structures of lipidated aromatic derivatives A117-A119. 


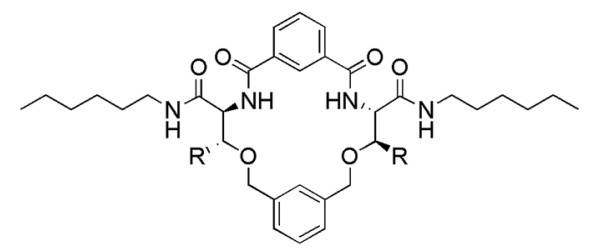

A124: $\mathrm{R}=\mathrm{H}$

A125: $\mathrm{R}=\mathrm{CH}_{3}$

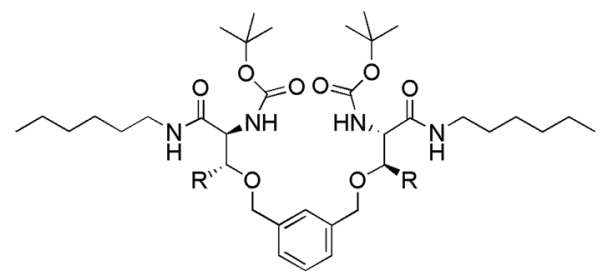

A126: $\mathrm{R}=\mathrm{H}$

A127: $\mathrm{R}=\mathrm{CH}_{3}$

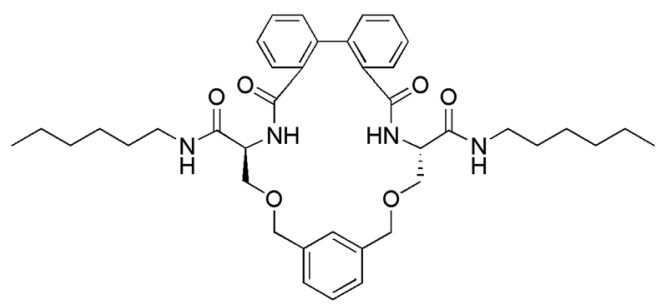

A128

Fig. 47 Chemical structures of serine and threonine-based lipidated compounds A124-A128.

It was reported that $\mathbf{A 1 2 3}$ formed microtubes in water : THF mixture when water content was $70-80 \%$, and hollow microspheres when water content increased upto $90 \%$ as demonstrated by FE-SEM and TEM.

Recently, our group has reported the synthesis and selfassembly of serine and threonine-based aromatic lipidated cyclic as well as acyclic compounds A124-A128 (Fig. 47). The serine-based macrocycle $\mathbf{A 1 2 4}$ and acyclic compound $\mathbf{A 1 2 6}$ did not show the vesicular assembly but corresponding threonine derivatives $\mathbf{A 1 2 5}$ and $\mathbf{A 1 2 7}$ readily formed the vesicles in methanol at $1 \mathrm{mM}$ concentration. However, when non-planarity is introduced in the serine-based macrocycle by incorporating the biphenyl spacer unit into it (A128), it showed the vesicular morphology as demonstrated by SEM, HR-TEM and AFM images. ${ }^{81}$ This underscores the significance of conformation in achieving the vesicular assembly.

\section{Conclusions}

This review highlights recent examples of vesicle forming molecules. The wide range of molecules discussed here, opens up avenues for newer molecular design. The broad range of conditions such as different organic and aqueous media expands the scope of its applications in chemistry, biology and material science. The use of vesicles for encapsulation of drugs further expands its applications in the field of medical sciences. In addition to these applications, vesicles are considered as protocell model and hence, are useful in studies related to 'origin of life'.

\section{Acknowledgements}

We thank the Department of Science and Technology (DST), New Delhi for the financial assistance. ARS thanks CSIR for the fellowship. SD thanks DST for the INSPIRE Fellowship.

\section{References}

1 (a) J. S. Lindsey, New J. Chem., 1991, 15, 153-180; (b) G. Whitesides, J. Mathias and C. Seto, Science, 1991, 254, 1312-1319; (c) J.-M. Lehn, Science, 2002, 295, 2400-2403.

2 (a) M. R. Ghadiri, J. R. Granja and L. K. Buehler, Nature, 1994, 369, 301-304; (b) P. A. Gale, Acc. Chem. Res., 2006, 39, 465475.

3 (a) S. J. Rowan, S. J. Cantrill, G. R. L. Cousins, J. K. M. Sanders and J. F. Stoddart, Angew. Chem., Int. Ed., 2002, 41, 898-952; (b) Y. Jin, C. Yu, R. J. Denman and W. Zhang, Chem. Soc. Rev., 2013, 42, 6634.

4 (a) K. M. Mullen and P. D. Beer, Chem. Soc. Rev., 2009, 38, 1701-1713; (b) R. S. Forgan, J.-P. Sauvage and J. F. Stoddart, Chem. Rev., 2011, 111, 5434-5464.

5 (a) D. S. Lawrence, T. Jiang and M. Levett, Chem. Rev., 1995, 95, 2229-2260; (b) C. Piguet, G. Bernardinelli and G. Hopfgartner, Chem. Rev., 1997, 97, 2005-2062; (c) J.-M. Lehn, Angew. Chem., Int. Ed. Engl., 1988, 27, 89-112; (d) B. M. Rosen, C. J. Wilson, D. A. Wilson, M. Peterca, M. R. Imam and V. Percec, Chem. Rev., 2009, 109, 6275-6540. 6 (a) J. A. A. W. Elemans, A. E. Rowan and R. J. M. Nolte, J. Mater. Chem., 2003, 13, 2661-2670; (b) T. Aida, E. W. Meijer and S. I. Stupp, Science, 2012, 335, 813-817; (c) J. D. Hartgerink, Science, 2001, 294, 1684-1688.

7 (a) G. M. Whitesides, Science, 2002, 295, 2418-2421; (b) E. Busseron, Y. Ruff, E. Moulin and N. Giuseppone, Nanoscale, 2013, 5, 7098-7140.

8 (a) I.-K. Kim, S.-H. Kim, S.-M. Choi, B.-S. Youn and H.-S. Kim, Curr. Stem Cell Res. Ther., 2016, 11, 329-342; (b) N. V. N. Jyothi, P. M. Prasanna, S. N. Sakarkar, K. S. Prabha, P. S. Ramaiah and G. Y. Srawan, J. Microencapsulation, 2010, 27, 187-197.

9 S. B. Fonseca, M. P. Pereira and S. O. Kelley, Adv. Drug Delivery Rev., 2009, 61, 953-964.

10 T. Kunitake, Angew. Chem., Int. Ed. Engl., 1992, 31, 709-726. 11 B. J. Ravoo, in Supramol. Chem., ed. P. A. Gale and J. W. Steed, John Wiley \& Sons, Ltd, Chichester, UK, 2012.

12 (a) H. Ringsdorf, B. Schlarb and J. Venzmer, Angew. Chem., Int. Ed., 1988, 27, 113-158; (b) T. S. Davies, A. M. Ketner and S. R. Raghavan, J. Am. Chem. Soc., 2006, 128, 66696675; (c) C. B. Minkenberg, W. E. Hendriksen, F. Li, E. Mendes, R. Eelkema and J. H. van Esch, Chem. 
Commun., 2012, 48, 9837; (d) A. Sorrenti, O. Illa and R. M. Ortuño, Chem. Soc. Rev., 2013, 42, 8200-8219.

13 (a) D. E. Discher, Science, 2002, 297, 967-973; (b) Y. Mai and A. Eisenberg, Chem. Soc. Rev., 2012, 41, 5969-5985; (c) J. Xu, Q. Fu, J. M. Ren, G. Bryant and G. G. Qiao, Chem. Commun., 2013, 49, 33-35; (d) C. G. Palivan, R. Goers, A. Najer, X. Zhang, A. Car and W. Meier, Chem. Soc. Rev., 2016, 45, 377-411; (e) J. Du and R. K. O'Reilly, Soft Matter, 2009, 5, 3544-3561.

14 (a) J. J. L. M. Cornelissen, M. Fischer, N. A. J. M. Sommerdijk and R. J. M. Nolte, Science, 1998, 280, 1427-1430; (b) D. Mandal, R. K. Tiwari, A. Nasrolahi Shirazi, D. Oh, G. Ye, A. Banerjee, A. Yadav and K. Parang, Soft Matter, 2013, 9, 9465-9475; (c) S. Maity, P. Jana, S. K. Maity and D. Haldar, Soft Matter, 2011, 7, 10174-10181; (d) S. V. Luis and I. Alfonso, Acc. Chem. Res., 2014, 47, 112-124; (e) D. Mandal, A. Nasrolahi Shirazi and K. Parang, Org. Biomol. Chem., 2014, 12, 3544-3561; (f) E. K. Chung, E. Lee, Y. Lim and M. Lee, Chem.-Eur. J., 2010, 16, 5305-5309.

15 (a) J.-L. Zhou, X.-J. Chen and Y.-S. Zheng, Chem. Commun., 2007, 48, 5200-5202; (b) V. A. Burilov, D. A. Mironova, R. R. Ibragimova, S. E. Solovieva, B. König and I. S. Antipin, RSC Adv., 2015, 5, 101177-101185; (c) D.-S. Guo and Y. Liu, Chem. Soc. Rev., 2012, 41, 5907-5921; (d) J. Mo, P. K. Eggers, Z. Yuan, C. L. Raston and L. Y. Lim, Sci. Rep., 2016, 6, 23489; (e) L. Baldini, A. Casnati, F. Sansone and R. Ungaro, Chem. Soc. Rev., 2007, 36, 254266.

16 (a) L. Jiang, Y. Peng, Y. Yan and J. Huang, Soft Matter, 2011, 7, 1726-1731; (b) P. Xing, T. Sun and A. Hao, RSC Adv., 2013, 3, 24776-24793.

17 (a) K. Kim, N. Selvapalam, Y. H. Ko, K. M. Park, D. Kim and J. Kim, Chem. Soc. Rev., 2007, 36, 267-279; (b) Q. Zhou, H. Wang, T. Gao, Y. Yu, B. Ling, L. Mao, H. Zhang, X. Meng and X. Zhou, Chem. Commun., 2011, 47, 1131511317.

18 (a) T. Homma, K. Harano, H. Isobe and E. Nakamura, J. Am. Chem. Soc., 2011, 133, 6364-6370; (b) V. Mohanta, D. Dey, S. Ramakumar and S. Patil, Langmuir, 2015, 31, 1360013608.

19 (a) F. Ruggeri, A. Akesson, P.-Y. Chapuis, C. A. Skrzynski Nielsen, M. P. Monopoli, K. A. Dawson, T. G. Pomorski and M. Cárdenas, Soft Matter, 2013, 9, 8862-8870; (b) J. M. J. Fréchet, J. Polym. Sci., Part A: Polym. Chem., 2003, 41, 3713-3725; (c) K. T. Kim, M. A. Winnik and I. Manners, Soft Matter, 2006, 2, 957-965; (d) Q. Xiao, S. Zhang, Z. Wang, S. E. Sherman, R.-O. Moussodia, M. Peterca, A. Muncan, D. R. Williams, D. A. Hammer, S. Vértesy, et al., Proc. Natl. Acad. Sci. U. S. A., 2016, 113, 1162-1167.

20 P. Walde, K. Cosentino, H. Engel and P. Stano, ChemBioChem, 2010, 11, 848-865.

21 A. D. Bangham and R. W. Horne, J. Mol. Biol., 1964, 8, 660-668. 22 M. Antonietti and S. Förster, Adv. Mater., 2003, 15, 13231333.

23 (a) D. W. Deamer and J. P. Dworkin, in Prebiotic Chem., ed. P. Walde, Springer-Verlag, Berlin/Heidelberg, 2005, pp. 1-27; (b) P. Walde, Origins Life Evol. Biospheres, 2006, 36, 109-150.
24 J. B. F. N. Engberts and D. Hoekstra, BBA, Biochim. Biophys. Acta, Rev. Biomembr., 1995, 1241, 323-340.

25 T. Kunitake and Y. Okahata, J. Am. Chem. Soc., 1977, 99, 3860-3861.

26 S. H. Seo, J. Y. Chang and G. N. Tew, Angew. Chem., Int. Ed., 2006, 45, 7526-7530.

27 F. J. M. Hoeben, I. O. Shklyarevskiy, M. J. Pouderoijen, H. Engelkamp, A. P. H. J. Schenning, P. C. M. Christianen, J. C. Maan and E. W. Meijer, Angew. Chem., Int. Ed., 2006, 45, 1232-1236.

28 F. García, G. Fernández and L. Sánchez, Chem.-Eur. J., 2009, 15, 6740-6747.

29 S.-H. Tung, H.-Y. Lee and S. R. Raghavan, J. Am. Chem. Soc., 2008, 130, 8813-8817.

30 F. García, M. R. Torres, E. Matesanz and L. Sánchez, Chem. Commun., 2011, 47, 5016-5018.

31 A. Mitra, D. K. Panda, L. J. Corson and S. Saha, Chem. Commun., 2013, 49, 4601-4603.

32 M. A. Markowitz, R. Bielski and S. L. Regen, Langmuir, 1989, 5, 276-278.

33 Y. Tanaka, M. Miyachi and Y. Kobuke, Angew. Chem., Int. Ed., 1999, 38, 504-506.

34 M. Lee, S.-J. Lee and L.-H. Jiang, J. Am. Chem. Soc., 2004, 126, 12724-12725.

35 M. Strobel, K. Kita-Tokarczyk, A. Taubert, C. Vebert, P. A. Heiney, M. Chami and W. Meier, Adv. Funct. Mater., 2006, 16, 252-259.

36 S. Houmadi, D. Coquière, L. Legrand, M. C. Fauré, M. Goldmann, O. Reinaud and S. Rémita, Langmuir, 2007, 23, 4849-4855.

37 B. Guan, M. Jiang, X. Yang, Q. Liang and Y. Chen, Soft Matter, 2008, 4, 1393-1395.

38 Y. J. Jeon, P. K. Bharadwaj, S. Choi, J. W. Lee and K. Kim, Angew. Chem., Int. Ed., 2002, 41, 4474-4476.

39 H.-K. Lee, K. M. Park, Y. J. Jeon, D. Kim, D. H. Oh, H. S. Kim, C. K. Park and K. Kim, J. Am. Chem. Soc., 2005, 127, 50065007.

40 H. Parrot-Lopez, C. C. Ling, P. Zhang, A. Baszkin, G. Albrecht, C. De Rango and A. W. Coleman, J. Am. Chem. Soc., 1992, 114, 5479-5480.

41 B. J. Ravoo and R. Darcy, Angew. Chem., Int. Ed., 2000, 39, 4324-4326.

42 B. Jing, X. Chen, X. Wang, C. Yang, Y. Xie and H. Qiu, Chem.Eur. J., 2007, 13, 9137-9142.

43 S. Li, L. Zhang, B. Wang, M. Ma, P. Xing, X. Chu, Y. Zhang and A. Hao, Soft Matter, 2015, 11, 1767-1777.

44 A. M. Cassell, C. L. Asplund and J. M. Tour, Angew. Chem., Int. Ed., 1999, 38, 2403-2405.

45 S. Zhou, C. Burger, B. Chu, M. Sawamura, N. Nagahama, M. Toganoh, U. E. Hackler and H. Isobe, Science, 2001, 291, 1944-1947.

46 J. Hao, H. Li, W. Liu and A. Hirsch, Chem. Commun., 2004, 602-603.

47 A. Muñoz, B. M. Illescas, M. Sánchez-Navarro, J. Rojo and N. Martín, J. Am. Chem. Soc., 2011, 133, 16758-16761.

48 E. P. Holowka, D. J. Pochan and T. J. Deming, J. Am. Chem. Soc., 2005, 127, 12423-12428. 
49 E. P. Holowka, V. Z. Sun, D. T. Kamei and T. J. Deming, Nat. Mater., 2007, 6, 52-57.

50 B.-S. Kim, W.-Y. Yang, J.-H. Ryu, Y.-S. Yoo and M. Lee, Chem. Commun., 2005, 2035-2037.

51 J. A. Opsteen, R. P. Brinkhuis, R. L. M. Teeuwen, D. W. P. M. Löwik and J. C. M. van Hest, Chem. Commun., 2007, 3136-3138.

52 R. Sigel, M. Łosik and H. Schlaad, Langmuir, 2007, 23, 71967199.

53 C. Nardin, T. Hirt, J. Leukel and W. Meier, Langmuir, 2000, 16, 1035-1041.

54 E. Rakhmatullina and W. Meier, Langmuir, 2008, 24, 62546261.

55 K. Dan, N. Bose and S. Ghosh, Chem. Commun., 2011, 47, 12491.

56 K. Dan and S. Ghosh, Angew. Chem., Int. Ed., 2013, 52, 73007305.

57 R. J. Bergeron, O. Phanstiel, G. W. Yao, S. Milstein and W. R. Weimar, J. Am. Chem. Soc., 1994, 116, 8479-8484.

58 M. Reches and E. Gazit, Nano Lett., 2004, 4, 581-585.

59 S. Ghosh, M. Reches, E. Gazit and S. Verma, Angew. Chem., Int. Ed., 2007, 46, 2002-2004.

60 E. Abel, S. L. De Wall, W. B. Edwards, S. Lalitha, D. F. Covey and G. W. Gokel, J. Org. Chem., 2000, 65, 5901-5909.

61 Y.-R. Yoon, Y. Lim, E. Lee and M. Lee, Chem. Commun., 2008, 1892-1894.

62 X. Yan, P. Zhu and J. Li, Chem. Soc. Rev., 2010, 39, 1877.

63 I. Alfonso, M. Bru, M. I. Burguete, E. García-Verdugo and S. V. Luis, Chem.-Eur. J., 2010, 16, 1246-1255.

64 J. Naskar, S. Roy, A. Joardar, S. Das and A. Banerjee, Org. Biomol. Chem., 2011, 9, 6610.

65 S. Choi, W. Jeong, S.-K. Kang, M. Lee, E. Kim, D. Y. Ryu and Y. Lim, Biomacromolecules, 2012, 13, 1991-1995.

66 P. Koley and A. Pramanik, Soft Matter, 2012, 8, 5364-5374.
67 V. Haridas, S. Sahu and A. R. Sapala, Chem. Commun., 2012, 48, 3821-3823.

68 V. Haridas, M. B. Bijesh, A. Chandra, S. Sharma and A. Shandilya, Chem. Commun., 2014, 50, 13797-13800.

69 V. Haridas, A. R. Sapala and J. P. Jasinski, Chem. Commun., 2015, 51, 6905-6908.

70 A. R. Sapala, J. Kundu, P. Chowdhury and V. Haridas, New J. Chem., 2016, 40, 9907-9911.

71 (a) I. Bhardwaj, D. Jha, P. Admane, A. K. Panda and V. Haridas, Bioorg. Med. Chem. Lett., 2016, 26, 672-676; (b) V. Haridas, P. P. P. Kumar, I. Bhardwaj and P. Venugopalan, ChemistrySelect, 2017, 2, 130-135.

72 M. Yang, W. Wang, F. Yuan, X. Zhang, J. Li, F. Liang, B. He, B. Minch and G. Wegner, J. Am. Chem. Soc., 2005, 127, 15107-15111.

73 V. Percec, D. A. Wilson, P. Leowanawat, C. J. Wilson, A. D. Hughes, M. S. Kaucher, D. A. Hammer, D. H. Levine, A. J. Kim, F. S. Bates, et al., Science, 2010, 328, 1009-1014.

74 V. Haridas, Y. K. Sharma, R. Creasey, S. Sahu, C. T. Gibson and N. H. Voelcker, New J. Chem., 2011, 35, 303-309.

75 R. P. Verma, A. Shandilya and V. Haridas, Tetrahedron, 2015, 71, 8758-8765.

76 A. Ajayaghosh, P. Chithra and R. Varghese, Angew. Chem., Int. Ed., 2007, 46, 230-233.

77 A. Ajayaghosh, R. Varghese, V. K. Praveen and S. Mahesh, Angew. Chem., Int. Ed., 2006, 45, 3261-3264.

78 W. Cai, G.-T. Wang, Y.-X. Xu, X.-K. Jiang and Z.-T. Li, J. Am. Chem. Soc., 2008, 130, 6936-6937.

79 X.-N. Xu, L. Wang and Z.-T. Li, Chem. Commun., 2009, 66346636.

80 S. Song, H.-F. Zheng, H.-T. Feng and Y.-S. Zheng, Chem. Commun., 2014, 50, 15212-15215.

81 M. B. Bijesh, R. Mishra, N. D. Kurur and V. Haridas, RSC $A d v .$, 2016, 6, 41761-41764. 